\title{
Exogenous Treatment with Glutamate Induces Immune Responses in Arabidopsis
}

\author{
Yukihisa Goto, ${ }^{1,2}$ Noriko Maki, ${ }^{1}$ Yasunori Ichihashi, ${ }^{1,3}$ Daisuke Kitazawa, ${ }^{4}$ Daisuke Igarashi, ${ }^{4}$ \\ Yasuhiro Kadota, ${ }^{1, \dagger}$ and Ken Shirasu, ${ }^{1,2, \dagger}$ \\ ${ }^{1}$ RIKEN Center for Sustainable Resource Science, Plant Immunity Research Group, Suehiro-cho 1-7-22 Tsurumi-ku, \\ Yokohama, Kanagawa, 230-0045, Japan \\ ${ }^{2}$ Graduate School of Science, The University of Tokyo, 7-3-1, Hongo, Bunkyo-ku, Tokyo, 113-8654, Japan \\ 3 JST, PRESTO, 4-1-8 Honcho, Kawaguchi, Saitama 332-0012, Japan \\ ${ }^{4}$ Frontier Research Labs, Institute for Innovation, Ajinomoto Co., Inc., 1-1 Suzuki-cho, Kawasaki 210-8681, Japan
}

Accepted 12 November 2019.

Plant resistance inducers (PRIs) are compounds that protect plants from diseases by activating immunity responses. Exogenous treatment with glutamate (Glu), an important amino acid for all living organisms, induces resistance against fungal pathogens in rice and tomato. To understand the molecular mechanisms of Glu-induced immunity, we used the Arabidopsis model system. We found that exogenous treatment with Glu induces resistance against pathogens in Arabidopsis. Consistent with this, transcriptome analyses of Arabidopsis seedlings showed that Glu significantly induces the expression of wound-, defense-, and stress-related genes. Interestingly, Glu activates the expression of genes induced by pathogen-associated molecular patterns (PAMPs) or damage-associated molecular patterns at much later time points than the flg22 peptide, which is a bacterial-derived PAMP. The Glu receptor-like (GLR) proteins GLR3.3 and GLR3.6 are involved in the early expression of Glu-inducible genes; however, the sustained expression of these genes does not require the GLR proteins. Glu-inducible gene expression is also not affected by mutations in genes that encode PAMP receptors (EFR, FLS2, and CERK1), regulators of pattern-triggered immunity (BAK1, BKK1, BIK1, and PBL1), or a salicylic acid biosynthesis enzyme (SID2). The treatment of roots with Glu activates the expression of PAMP-, salicylic acid-, and jasmonic acid-inducible genes in leaves. Moreover, the treatment of roots with Glu primes chitin-induced responses in leaves, possibly through transcriptional activation of LYSIN-MOTIF RECEPTOR-LIKE KINASE 5

Current address for Y. Ichihashi: RIKEN BioResource Research Center, Tsukuba, Ibaraki 305-0074, Japan.

${ }^{\dagger}$ Corresponding authors: Y. Kadota; yasuhiro.kadota@ riken.jp; and K. Shirasu; ken.shirasu@ @iken.jp

Funding: Japan Society for the Promotion of Science, KAKENHI grant numbers JP16J0071, JP16H06186, JP16KT0037, JP15H05959, JP19H02962, and JP17H06172 and the Cabinet Office, Government of Japan, Crossministerial Strategic Innovation Promotion Program (SIP), "Technologies for Smart Bio-industry and Agriculture" (funding agency: Bio-oriented Technology Research Advancement Institution, NARO).

*The $\boldsymbol{e}$-Xtra logo stands for "electronic extra" and indicates that 16 supplementary figures and nine supplementary tables are published online.

The author(s) declare no conflict of interest.

๑) 2020 The American Phytopathological Society
(LYK5), which encodes a chitin receptor. Because Glu treatment does not cause discernible growth retardation, Glu can be used as an effective PRI.

Keywords: elicitors, induced systemic resistance, MAMPs, PAMPs

Plant resistance inducers (PRIs) are agents that protect plants from pathogens by activating their own defense systems. (Alexandersson et al. 2016; Noutoshi et al. 2012). Whereas the intensive use of antimicrobial compounds can promote the emergence of drug-resistant pathogens, the use of PRIs, which target plants but not pathogens, does not carry this risk. Because PRIs activate a variety of immune responses in plants, their application often confers a broad-spectrum resistance that reduces the chances of infection by multiple kinds of pathogens (Oostendorp et al. 2001). In addition, because PRIs are not generally toxic, their use has a lower impact on the environment and human health than the impacts of more toxic antimicrobial compounds. To date, a variety of PRIs have been developed and safely applied to crop protection in the field.

Among the known PRIs, 2,6-dichloro isonicotinic acid (INA) and benzothiadiazole (BTH) have been intensively studied as model compounds (Friedrich et al. 1996; Görlach et al. 1996; Klessig et al. 2018; Ward et al. 1991). Both INA and BTH structurally and functionally mimic salicylic acid (SA), a plant defense hormone that plays a central role in resistance to biotrophic and hemibiotrophic pathogens (Métraux et al. 1990). SA induces the expression of pathogenesis-related $(P R)$ genes (Ward et al. 1991), and primes plants to respond more rapidly and robustly to pathogen infection (Shirasu et al. 1997). In contrast to INA and BTH, the commercially successful PRI probenazole induces plant resistance to pathogens by inducing SA accumulation (Yoshioka et al. 2001).

Pathogen-derived molecules known as pathogen-associated molecular patterns (PAMPs), which are small molecular motifs conserved within a class of microbes, can also be used as PRIs in crops (Henry et al. 2012). Plants recognize PAMPs and induce immune responses, resulting in so-called pattern-triggered immunity (PTI) (Monaghan and Zipfel 2012; Segonzac and Zipfel 2011). For example, treatment of green bean with chitosan (a derivative of chitin, a conserved fungal oligosaccharide) improves their growth and yield, and also enhances resistance against the root-rot pathogens Fusarium solani and Rhizoctonia solani (El-Mohamedy et al. 2017). Extensive studies over the past several decades have clarified the molecular mechanisms of PTI. PAMPs are recognized by plasma 
membrane-localized pattern recognition receptors (PRRs) (Boutrot and Zipfel 2017). For example, flagellin insensitive 2 (FLS2) and the elongation factor $\mathrm{Tu}(\mathrm{EF}-\mathrm{Tu})$ receptor (EFR) are leucine-rich repeat receptor kinases (LRR-RKs) that are receptors for bacterial flagellin (or the epitope flg22) and EF-Tu (or the epitopes elf18/elf26), respectively (Couto and Zipfel 2016). The recognition of flg 22 and elf18 by these PRRs requires the coreceptors BRI1-associated receptor kinase 1 (BAK1) and BAK1-like 1 (BKK1), which are also LRR-RKs (Chinchilla et al. 2007; Heese et al. 2007; Kadota et al. 2014; Li et al. 2014; Roux et al. 2011; Schulze et al. 2010). Fungal chitin is recognized by the chitin receptor complex, which includes lysin-motif receptor-like kinases (LYKs) such as LYK5 and chitin elicitor receptor kinase (CERK1) in Arabidopsis (Cao et al. 2014; Miya et al. 2007). Activated PRRs, in turn, induce downstream responses such as the rapid production of reactive oxygen species (ROS), activation of mitogen-activated protein kinases (MAPKs), and expression of PAMP-inducible genes (Doke 1983; Kadota et al. 2014, 2015; Li et al. 2014; Liu et al. 2013; Zhang et al. 2010).

Similar to PAMPs, damage-associated molecular patterns (DAMPs) also induce PTI and can be used as PRIs. Known DAMPs are oligogalacturonides (OGs); extracellular ATP (eATP); and the Arabidopsis-derived elicitor peptides pep1, pep2, and pep3 and high-mobility group box 3 (HMGB3), which are released upon tissue wounding or pathogen infection (Benedetti et al. 2015; Choi et al. 2016; Tanaka et al. 2010; Yamada et al. 2016). OGs are derived from the partial hydrolysis of pectin in plant cell walls, and are perceived by the cell-wall-associated kinase 1 (Brutus et al. 2010). eATP is recognized by DOES NOT RESPOND TO NUCLEOTIDES 1 (DORN1), an L-type lectin-domain-containing receptor kinase (Choi et al. 2014). Pep1, pep2, and pep3 are peptides derived from PROPEP1, PROPEP2, and PROPEP3, respectively, and are recognized by the LRR-RK PEP1 receptor 1 (PEPR1) and PEPR2 together with the coreceptors BAK1 and BKK1 (Choi et al. 2016; Huffaker et al. 2006; Krol et al. 2010; Ma et al. 2012; Yamada et al. 2016; Yamaguchi and Huffaker 2011; Yamaguchi et al. 2006, 2010). Infection of necrotrophic fungus Botrytis cinerea to Arabidopsis releases HMGB3 into the apoplastic region, which is presumably recognized by as-yet-unidentified receptors and induces PTI responses through BAK1 and BKK1 (Choi et al. 2016).

Amino acids have been used as fertilizers to increase crop yields (Dromantiené et al. 2013; Popko et al. 2018), and some amino acids such as the nonprotein amino acid $\beta$-aminobutyric acid (BABA) also function as PRIs. BABA protects many plant species against a wide variety of pathogens and pests, including viruses, protists, bacteria, oomycetes, fungi, nematodes, and arthropods (Cohen et al. 2016). Interestingly, BABA also enhances tolerance to a wide range of abiotic stresses, including salt, heat, and drought (Jakab et al. 2005; Zimmerli et al. 2008). In Arabidopsis, BABA is recognized by an aspartyl-tRNA synthetase named impaired in BABA-induced immunity 1 (IBI1) (Luna et al. 2014) but the downstream signaling is still largely unknown. The amino acid histidine induces resistance in Arabidopsis and tomato against B. cinerea and the soilborne bacterial pathogen Ralstonia solanacearum, through activation of the ethylene signaling pathway (Seo et al. 2016). Further, exogenous treatment with glutamate (Glu) enhances resistance against the rice blast fungus Magnaporthe oryzae in rice leaves (Kadotani et al. 2016) and the necrotrophic fungus Alternaria alternata in tomato fruit (Yang et al. 2017). In rice, Glu treatment of roots induces the expression of the SA-inducible genes $O s W R K Y 45$ and $O s P R 1 b$, and Glu-inducible resistance against $M$. oryzae is partially reduced in SA-deficient NahG plants expressing an SA hydroxylase (Kadotani et al. 2016). The partial reduction of Glu-induced resistance suggests that both
SA-dependent and -independent signaling pathways contribute to Glu-inducible resistance.

In Arabidopsis, Glu triggers rapid, large changes in the cytosolic $\mathrm{Ca}^{2+}$ concentration $\left(\left[\mathrm{Ca}^{2+}\right]_{\text {cyt }}\right)$ and membrane depolarization (Dennison and Spalding 2000; Meyerhoff et al. 2005). These effects depend on the Glu receptor-like (GLR) protein GLR3.3, which is an amino acid-gated cation-permeable ion channel (Qi et al. 2006). The other amino acids glycine, alanine, serine, asparagine, cysteine, and tripeptide glutathione also trigger changes in $\left[\mathrm{Ca}^{2+}\right]_{\text {cyt }}$ and membrane depolarization, and GLR3.3 is also involved in these effects ( $\mathrm{Li}$ et al. 2013; Qi et al. 2006; Stephens et al. 2008). One possible model for the activation of GLR3.3-mediated $\left[\mathrm{Ca}^{2+}\right]_{\text {cyt }}$ changes by multiple amino acids is that GLR3.3, which might be activated only by Glu, functions as a component of a complex containing other GLRs that can be activated by the other amino acids (Stephens et al. 2008). A recent study showed that Glu also works as a wounding signal that triggers long-distance defense signaling in a manner dependent on GLR3.3 and GLR3.6 (Mousavi et al. 2013; Toyota et al. 2018).

To further investigate the mechanisms of Glu-inducible immunity, we investigated pathogen resistance and gene expression in Arabidopsis treated with Glu. We show here that exogenous treatment with Glu enhances resistance against pathogens in Arabidopsis. The treatment of seedlings with Glu activates the expression of wound-, PAMP-, and DAMPinducible genes in a temporally distinct manner. As expected, the GLR proteins GLR3.3 and GLR3.6 are involved in the early expression of Glu-inducible genes. Surprisingly, however, the sustained expression of Glu-inducible genes does not require GLR3.3 and GLR3.6. Similarly, the PAMP receptors and coreceptors (EFR, FLS2, CERK1, BAK1, and BKK1) and the PTI signaling components (BIK1 and BKK1) are not required for this sustained expression. In addition, SID2-dependent SA production is not required for the late Glu-inducible gene expression, because a mutant that lacks the SA biosynthesis enzyme SID2 still responds to Glu in a manner similar to the wild type. Moreover, treatment of the roots of mature plants with Glu activates the expression of PAMP- and SA-inducible genes in leaves, and primes chitin-induced responses in the leaves. Our results suggest that Glu is an effective PRI that induces immune responses in Arabidopsis.

\section{RESULTS}

\section{Glu treatment enhances resistance against pathogens in Arabidopsis.}

To explore the molecular mechanisms of Glu-inducible disease resistance, we treated Arabidopsis plants with exogenous Glu. The leaves of soil-grown plants were pretreated with $20 \mathrm{mM}$ Glu or distilled water prior to inoculation with the fungal pathogen Colletotrichum higginsianum, which causes anthracnose leaf spot on many Brassicaceae plants, including Arabidopsis (Fig. 1A). Lesion development was inhibited in the Glu-treated plants compared with the controls, showing that Glu treatment enhances resistance to the fungus in Arabidopsis. In contrast, pretreatment of leaves with Glu did not enhance resistance to the virulent bacterial pathogen Pseudomonas syringae pv. tomato DC3000 (Supplementary Fig. S1A). Because Glu enhanced the growth of $P$. syringae pv. tomato DC3000 in in vitro culture, it is possible that exogenously supplied Glu might serve as a nutrient source for the bacterium (Supplementary Fig. S1B).

Glu also induces systemic resistance to fungal and bacterial pathogens. The roots of soil-grown plants were soaked in $20 \mathrm{mM}$ Glu or distilled water prior to the inoculation of leaves with $C$. higginsianum. Lesion development in distal leaves was restricted in Glu-treated plants compared with the controls, 
showing that Glu treatment systemically enhances resistance to the fungus in Arabidopsis (Fig. 1B). Glu treatment in the roots also significantly reduced the growth of $P$. syringae pv. tomato DC3000 in leaves compared with controls (Fig. 1C). These results suggest that Glu enhances resistance to pathogens in Arabidopsis.

A

\section{Colletotrichum higginsianum}
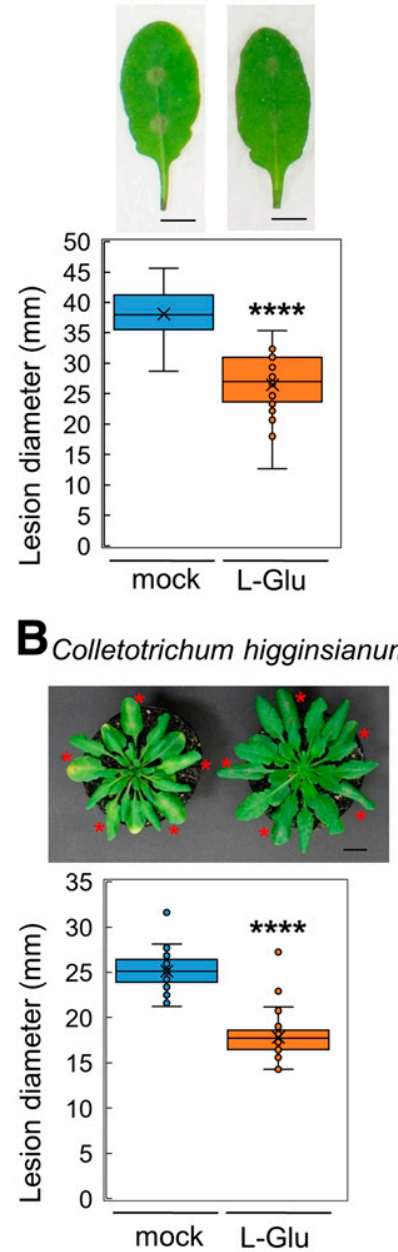

Fig. 1. L-glutamate (Glu) treatment enhances resistance against fungal and bacterial pathogens in Arabidopsis. A, Sizes of necrotic lesions caused by Colletotrichum higginsianum infection in inoculated leaves pretreated with L-Glu or distilled water (mock). Leaves of 4-week-old soil-grown Arabidopsis plants were pretreated with $20 \mathrm{mM} \mathrm{L-Glu}$ or distilled water for $48 \mathrm{~h}$ before drop inoculation with $C$. higginsianum. Lesions on 40 inoculated leaves were measured for each treatment. Black asterisks indicate a significant difference based on the Student's $t$ test $(* * * *$ indicate $P$ value $\leq$ $0.0001)$. B, Sizes of necrotic lesions caused by $C$. higginsianum infection in plants pretreated with L-Glu or distilled water (mock). Roots of 4-week-old soil-grown Arabidopsis plants were pretreated with $20 \mathrm{mM} \mathrm{L-Glu}$ or distilled water for $48 \mathrm{~h}$ before drop inoculation with $C$. higginsianum. Red asterisks indicate drop-inoculated leaves. Lesions on 40 inoculated leaves were measured for each treatment. Black asterisks indicate a significant difference based on the Student's $t$ test (**** indicate $P$ value $\leq 0.0001$ ). C, Bacterial growth of Pseudomonas syringae pv. tomato DC3000 in plants pretreated with L-Glu or distilled water (mock). Roots of 6-week-old soilgrown Arabidopsis plants were pretreated with $20 \mathrm{mM} \mathrm{L-Glu}$ or distilled water for $48 \mathrm{~h}$ before syringe-inoculation with $P$. syringae pv. tomato DC3000. Red asterisks indicate syringe-inoculated leaves. Data are means \pm standard error of eight biological replicates. Black asterisks indicate a significant difference based on the Student's $t$ test (*** indicate $P$ value $\leq$ 0.001). All experiments were repeated at least three times with similar results. Scale bars $=1 \mathrm{~cm}$.
Significant overlap in the genes induced

by Glu, PAMPs, DAMPs, and wounding.

Next, we performed a transcriptome analysis of Arabidopsis seedlings treated with Glu. Because a previous study showed that the SA signaling pathway partially contributes to Gluinducible resistance in rice (Kadotani et al. 2016), we aimed to identify genes that are differentially expressed after treatment with Glu versus SA. Fourteen-day-old Arabidopsis seedlings were treated with $20 \mathrm{mM}$ urea, $20 \mathrm{mM}$ Glu, or $1 \mathrm{mM}$ SA for 6 , 12,24 , or $48 \mathrm{~h}$; then, transcript levels were analyzed by RNA sequencing (RNA-Seq) (Supplementary Table S1).

Because Glu can be consumed by plants as a nitrogen source, we used urea to check the effect of increased nitrogen supply on gene expression. A multidimensional scaling (MDS) plot showed that three biological replicates of each treatment had similar global gene expression patterns (Fig. 2A). The MDS plot also showed that SA and Glu induced significant changes in global gene expression after 6 and 12 h, respectively (Fig. $2 \mathrm{~A})$. In contrast, urea treatment did not induce a large change in global gene expression, indicating that an increased nitrogen

A
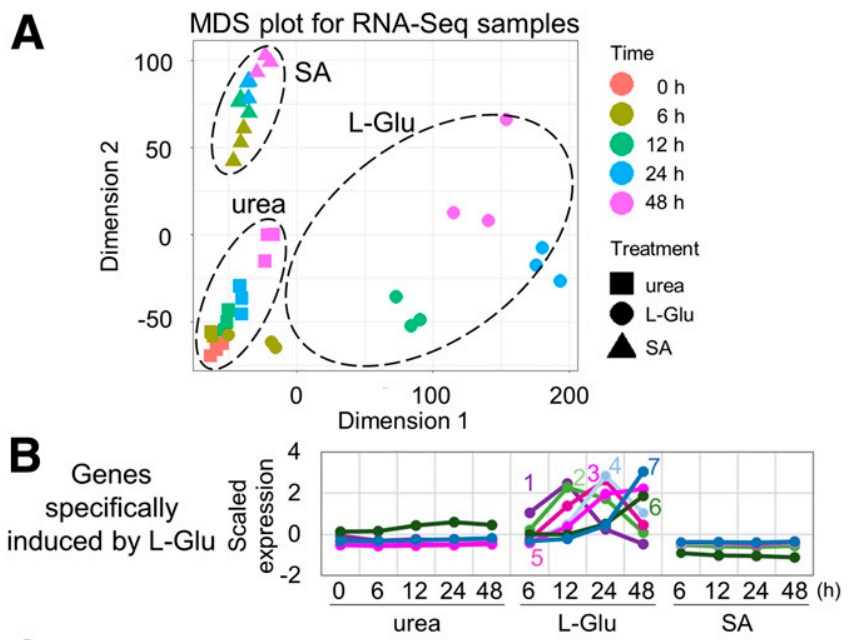

C Genes induced by

L-Glu and SA

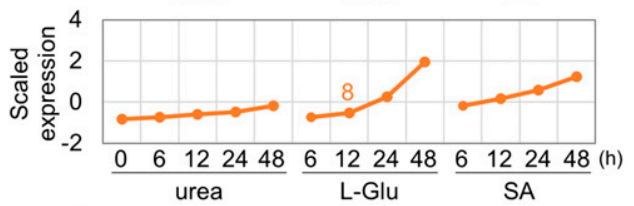

D

Genes specifically induced by SA

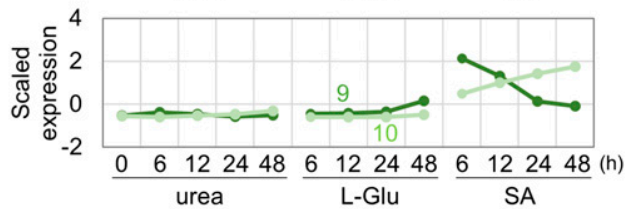

E

Genes Down regulated by L-Glu and SA

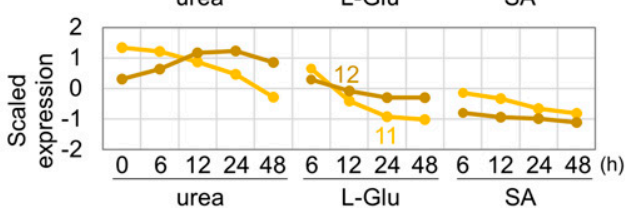

Fig. 2. Multidimensional scaling (MDS) plot with self-organizing map (SOM) clustering of genes in Arabidopsis seedlings treated with urea, L-glutamate (Glu), or salicylic acid (SA). The 14-day-old Arabidopsis seedlings were treated with $20 \mathrm{mM}$ urea, $20 \mathrm{mM} \mathrm{L-Glu}$, or $1 \mathrm{mM}$ SA for 6 , 12,24 , or $48 \mathrm{~h}$, and transcript expression levels were analyzed by RNA sequencing. A, MDS plot of global gene expression after each treatment. $\mathbf{B}$ to $\mathbf{E}$, Scaled expression profiles of genes in each of 12 clusters. Each cluster is indicated by a different color. B, Genes in clusters 1 to 7 were specifically induced by L-Glu. C, Genes in cluster 8 were induced by both L-Glu and SA. D, Genes in clusters 9 and 10 were induced by SA. E, Genes in clusters 11 and 12 were downregulated by L-Glu and SA. 
supply had only a limited effect on gene expression. Glu treatment upregulated 5,881 genes and downregulated 5,004 genes by at least twofold at one or more time points, when compared with urea treatment (Supplementary Table S2). Similarly, SA treatment upregulated 2,058 genes and downregulated 3,138 genes (Supplementary Table S3).

To identify genes with interesting expression profiles, principal component analysis (PCA) with self-organizing map (SOM) clustering was carried out on the highly differentially expressed genes (those within the top $25 \%$ in the coefficient of variation across samples) (Supplementary Fig. S2). Scaled expression values, representing the average principal component (PC) values among each gene in a cluster, were used to construct a multilevel three-by-four hexagonal SOM (Wehrens and Buydens 2007). The genes were grouped into 12 clusters based on their differential gene expression profiles after the urea, Glu, and SA treatments (Supplementary Fig. S2; Supplementary Table S4). Genes in clusters 1 to 7 were specifically induced by Glu (Fig. 2B), genes in cluster 8 were induced by both Glu and SA (Fig. 2C), genes in clusters 9 and 10 were induced only by SA (Fig. 2D), and genes in clusters 11 and 12 were downregulated by both Glu and SA (Fig. 2E). These clustering patterns suggest that some Glu-inducible genes are $\mathrm{SA}$ responsive but the others are not.

To characterize the genes that are differentially expressed after Glu treatment, we performed Gene Ontology (GO) enrichment analyses on each cluster (false discovery rate [FDR] $\leq$ 0.01) (Table 1; Supplementary Table S5). The GO terms significantly enriched in Glu-inducible gene clusters were related to defense and stress responses (Table 1). This is consistent with the Glu-enhanced immunity against fungi and bacteria (Fig. 1). For example, the GO terms "response to chitin (GO: 0010200)", "defense response (GO:0006952)", and "response to stress (GO:0006950)" were significantly over-represented among genes in clusters 2, 3, 4, 5, and 7 (Table 1; Supplementary Table S5). In contrast, cell wall organization or biogenesis-related GO terms (GO:0071554, GO:0042546, and GO:0071555) were enriched in cluster 12, which includes genes that are downregulated by both Glu and SA when compared with urea treatment.

Glu was recently shown to function as a signal for the longdistance propagation of wound-responsive gene expression (Toyota et al. 2018). Consistent with this, the GO term "response to wounding (GO:0009611)" was enriched in clusters 4, 5, and 7. To explore this further, we compared the Gluinducible genes with a previously published set of woundinducible genes (Fig. 3A). Ikeuchi et al. (2017) performed transcriptome analyses of hypocotyl explants after cutting and found that 7,736 genes were induced after wounding. Among the 5,881 genes that were upregulated by Glu treatment (log twofold change $\geq 1$, FDR $\leq 0.01), 52 \%(3,044)$ were also wound inducible, suggesting a significant overlap in the Gluand wound-induced signaling pathways. Wounded plants are thought to recognize a variety of DAMPs, which induce PTI to defend against opportunistic infections by pathogens or insects. We compared the Glu-inducible genes with genes induced by

Table 1. Gene ontology (GO) enrichment analysis of 12 self-organizing map clusters ${ }^{\mathrm{a}}$

\begin{tabular}{|c|c|c|c|}
\hline $\begin{array}{l}\text { Expression patterns, cluster } \\
\text { (number of genes) }^{\mathbf{b}}\end{array}$ & GO term & Fold & FDR \\
\hline \multicolumn{4}{|l|}{ Genes specifically induced by Glu } \\
\hline Cluster 1 (198) & No significant GO terms & $\ldots$ & $\ldots$ \\
\hline \multirow[t]{3}{*}{ Cluster 2 (362) } & Response to organic substance (GO:0010033) & 2.1 & $6.0 \mathrm{E}-04$ \\
\hline & Response to chitin (GO:0010200) & 7.1 & $8.6 \mathrm{E}-04$ \\
\hline & Signal transduction (GO:0007165) & 2.2 & $8.9 \mathrm{E}-04$ \\
\hline \multirow[t]{3}{*}{ Cluster 3 (710) } & Defense response (GO:006952) & 2.9 & 3.7E-18 \\
\hline & Response to chitin (GO:0010200) & 9.6 & $2.8 \mathrm{E}-16$ \\
\hline & Response to drug (GO:0042493) & 4.2 & $8.0 \mathrm{E}-15$ \\
\hline \multirow[t]{3}{*}{ Cluster 4 (734) } & Defense response (GO:0006952) & 3.3 & $7.9 \mathrm{E}-25$ \\
\hline & Response to drug (GO:0042493) & 5.2 & $4.0 \mathrm{E}-24$ \\
\hline & Response to stress (GO:0006950) & 2.2 & $1.2 \mathrm{E}-22$ \\
\hline \multirow[t]{3}{*}{ Cluster 5 (640) } & Response to stress (GO:0006950) & 1.7 & $1.9 \mathrm{E}-04$ \\
\hline & Response to stimulus (GO:0050896) & 1.4 & 3.7E-04 \\
\hline & Response to wounding (GO:0009611) & 4.0 & $2.0 \mathrm{E}-03$ \\
\hline \multirow[t]{3}{*}{ Cluster 6 (219) } & Cell wall organization or biogenesis (GO:0071554) & 5.2 & $6.7 \mathrm{E}-08$ \\
\hline & Cell wall organization (GO:0071555) & 5.6 & $1.1 \mathrm{E}-06$ \\
\hline & Trichoblast differentiation (GO:0010054) & 13.6 & $2.1 \mathrm{E}-06$ \\
\hline \multirow[t]{3}{*}{ Cluster 7 (654) } & Response to heat (GO:0009408) & 10.3 & $1.8 \mathrm{E}-25$ \\
\hline & Response to temperature stimulus (GO:0009266) & 4.9 & $8.7 \mathrm{E}-20$ \\
\hline & Response to stress (GO:0006950) & 2.1 & $2.3 \mathrm{E}-15$ \\
\hline \multicolumn{4}{|l|}{ Genes induced by Glu and SA } \\
\hline Cluster $8(169)$ & Response to salicylic acid (GO:0009751) & 7.8 & $2.1 \mathrm{E}-02$ \\
\hline \multicolumn{4}{|l|}{ Genes specifically induced by SA } \\
\hline \multirow[t]{3}{*}{ Cluster $9(150)$} & Glutathione metabolic process (GO:0006749) & 21.4 & $2.2 \mathrm{E}-04$ \\
\hline & Secondary metabolic process (GO:0019748) & 6.0 & $2.8 \mathrm{E}-04$ \\
\hline & Detoxification (GO:00098754) & 18.7 & $3.4 \mathrm{E}-04$ \\
\hline \multirow[t]{3}{*}{ Cluster 10 (410) } & Defense response (GO:0006952) & 2.9 & $9.5 \mathrm{E}-09$ \\
\hline & Response to salicylic acid (GO:0009751) & 7.4 & $1.8 \mathrm{E}-08$ \\
\hline & Response external biotic stimulus (GO:0043207) & 2.6 & $1.0 \mathrm{E}-0.5$ \\
\hline \multicolumn{4}{|c|}{ Genes downregulated by Glu and SA } \\
\hline \multirow[t]{3}{*}{ Cluster $11(387)$} & Photosynthesis, light harvesting in photosystem I (GO:0009768) & 50.8 & $1.4 \mathrm{E}-16$ \\
\hline & Photosynthesis (GO:0015979) & 9.8 & $1.7 \mathrm{E}-15$ \\
\hline & Photosynthesis, light reaction(GO:0019684) & 14.0 & $5.0 \mathrm{E}-15$ \\
\hline \multirow[t]{3}{*}{ Cluster 12 (367) } & Cell wall organization or biogenesis(GO:0071554) & 3.9 & 2.4E-07 \\
\hline & Cell wall biogenesis (GO:0042546) & 5.8 & $1.6 \mathrm{E}-04$ \\
\hline & Cell wall organization (GO:0071555) & 3.7 & $2.0 \mathrm{E}-04$ \\
\hline
\end{tabular}


several DAMPs, including OGs, pep2, and eATP (Choi et al. 2014; Denoux et al. 2008; Ross et al. 2014) (Fig. 3B and C; Supplementary Fig. S3A). Of the 1,399 OG-inducible genes, $75.9 \%$ were Glu inducible, $77.3 \%$ were wound inducible, and $61.2 \%$ were induced by both Glu and wounding (Fig. 3B). These results show a high degree of overlap between Glu-, OG-, and wound-inducible genes. Similarly, there was significant overlap among pep2-, Glu-, and wound-inducible genes (Fig. $3 \mathrm{C})$. Of the 1,569 pep2-inducible genes, $68.3 \%$ were Glu inducible, $71.7 \%$ were wound inducible, and $52.3 \%$ were both Glu and wound inducible. In contrast, we found much less overlap among the eATP-, Glu-, and wound-inducible genes (Supplementary Fig. S3A). We also compared the Glu- and wound-inducible genes with those induced by BABA, the amino acid that functions as a PRI (Cohen et al. 2016; Zimmerli et al. 2008). Limited overlap was found among these sets of genes (Supplementary Fig. S3B).
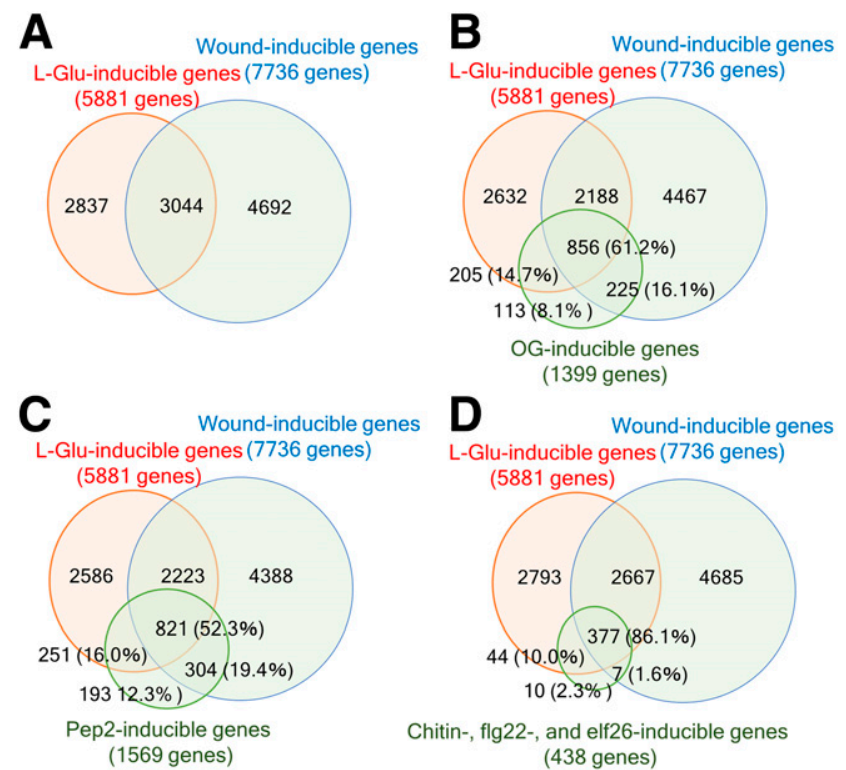

E

\begin{tabular}{|c|c|c|c|c|}
\hline $\begin{array}{c}\text { Categories } \\
\text { (number of genes) }\end{array}$ & $\begin{array}{c}\text { Glu-inducible genes } \\
\text { (fold change } \geq 10, \\
\text { FDR } \leq 0.01) \\
\text { (1645 genes) }\end{array}$ & $\begin{array}{c}\text { Expected number of } \\
\text { genes based on } \\
\text { size of list } \\
\text { and number of } \\
\text { genes in genome }\end{array}$ & Fold enrichment & $p$-value \\
\hline $\begin{array}{c}\text { Chitin-, flg22-, and } \\
\text { elf26-inducible } \\
\text { genes (438 genes) }\end{array}$ & 334 & 26 & 12.7 & $<2.2 \mathrm{E}-16$ \\
\hline $\begin{array}{c}\text { OGs- and pep2- } \\
\text { inducible genes } \\
\text { (963 genes) }\end{array}$ & 420 & 57 & 7.3 & $<2.2 \mathrm{E}-16$ \\
\hline $\begin{array}{c}\text { Wound-inducible } \\
\text { genes (7736 genes) }\end{array}$ & 923 & 461 & 2.0 & $<2.2 \mathrm{E}-16$ \\
\hline
\end{tabular}

Fig. 3. Overlap in the expression of glutamate (Glu)-inducible, woundinducible, pathogen-associated molecular pattern (PAMP)-inducible, and damage-associated molecular pattern (DAMP)-inducible genes. A, Venn diagram showing the overlap between Glu-inducible genes (fold change $\geq$ 2 , false discovery rate $[$ FDR $] \leq 0.01)$ and wound-inducible genes (FDR $\leq$ 0.05) (Ikeuchi et al. 2017). B, Venn diagram showing the overlap between Glu-inducible genes, wound-inducible genes, and oligogalacturonide (OG)inducible genes (fold change $\geq 2, P$ value $\leq 0.01$ ) (Denoux et al. 2008). $\mathbf{C}$, Venn diagram showing the overlap between Glu-inducible genes, woundinducible genes, and pep2-inducible genes (fold change $\geq 2, q \leq 0.05$ ) (Ross et al. 2014). D, Venn diagram showing the overlap between Glu-inducible genes, wound-inducible genes, and genes induced by all three of the PAMPs (chitin, flg22, and elf26) (fold change $\geq 2$ ) (Wan et al. 2008). E, Fisher's exact test of Glu-inducible genes (fold change $\geq 10$, FDR $\leq 0.01$ ). Statistical analyses based on Fisher's exact test were conducted on the overlap ratio of Glu-inducible genes to PAMP-, DAMP-, and wound-inducible genes.
Because OGs and pep2 induce sets of genes similar to those induced by PAMPs (Denoux et al. 2008; Ross et al. 2014), we also compared Glu-inducible genes with PAMP-inducible genes (Fig. 3D). Indeed, $96.1 \%$ of the 438 genes that are induced by all three of the PAMPs (chitin, flg22, and elf26) were also Glu inducible, $87.7 \%$ were wound inducible, and $86.1 \%$ were both Glu and wound inducible. Thus, we found a significant overlap between Glu-, PAMP-, DAMP-, and wound-inducible genes. These commonly inducible genes were mainly classified into clusters 2, 3, 4, 5, and 7 (Supplementary Fig. S4), and their expression peaked at 12 to 48 h (Fig. 2B; Supplementary Table S4).

The expression of many PAMP-, DAMP-, and woundinducible genes was highly upregulated by Glu treatment (Supplementary Fig. S5). We used a gene set enrichment method (the Fisher's exact test) to analyze enrichment based on the size of the list and the number of genes in the genome. The analysis showed that PAMP-inducible genes (induced by all three of chitin, flg22, and elf26) are 12.7-fold enriched in the list of genes that are induced by Glu more than 10 -fold $(P<$ 2.2E-16) (Fig. 3E). Similarly, the genes induced by both OGs and pep2 and the wound-inducible genes are enriched by 7.3fold $(P<2.2 \mathrm{E}-16)$ and 2.0 -fold $(P<2.2 \mathrm{E}-16)$, respectively, in the list of genes that are induced by Glu more than 10-fold (Fig. $3 \mathrm{E})$. In conclusion, Glu specifically induces the expression of PAMP-, DAMP-, and wound-inducible genes.

\section{Glu may induce the expression of PAMP-inducible genes in a different manner from PAMPs.}

Because Glu treatment activated the expression of many PAMP- and DAMP-inducible genes, we considered it possible that plants recognize Glu as a PAMP or a DAMP. However, Glu treatment did not cause strong activation of MPK3 or MPK6 (two MAPKs), nor did it cause detectable ROS production (Fig. 4A and B; Supplementary Fig. S6). Both of these are early events in PAMP and DAMP signaling. Next, we assessed the dynamics of induction of the PTI marker genes NHL10, CYP81F2, and $F R K 1$, whose expression levels are also upregulated after wounding or treatment with PAMPs or DAMPs (Denoux et al. 2008; Ross et al. 2014) (Fig. 4C). As reported previously, flg22 induced rapid and transient expression of $N H L 10, C Y P 81 F 2$, and $F R K 1$, peaking between 0.5 and $6 \mathrm{~h}$. In contrast, Glu induced the expression of these genes at much later time points (12 to $48 \mathrm{~h}$ ). Strikingly, Glu induced much higher expression levels of NHL1O at $48 \mathrm{~h}$ than flg 22 at $1 \mathrm{~h}$ (Fig. 4C). These results suggest that Glu induces the expression of PTI marker genes in a temporally distinct manner when compared with flg22. The slow induction pattern was also apparent in other PAMP- or Glu-inducible genes (Supplementary Fig. S7). Consistently, the expression of genes encoding PTI signaling components (Supplementary Fig. S8) also peaked at 24 or $48 \mathrm{~h}$ after Glu treatment.

Next, we investigated the dose-dependency of Glu using NHL10 and CYP81F2 (Supplementary Fig. S9). Under the conditions tested, concentrations of Glu above $10 \mathrm{mM}$ induced the expression of both genes at $48 \mathrm{~h}$ after treatment. Although the Glu-induced $C Y P 81 F 2$ expression was saturated by treatment with $20 \mathrm{mM}$ Glu, NHL10 expression was higher with $30 \mathrm{mM}$ Glu than with $20 \mathrm{mM}$ Glu (Supplementary Fig. S9). Toyota et al. (2018) showed that the drop application of 50 to $100 \mathrm{mM}$ Glu on precut Arabidopsis leaves caused the rapid induction of jasmonic acid (JA)-inducible genes (OPR3, JAZ5, and $J A Z 7$ ) and other defense-related genes (RBOHD and ZAT12) in distal leaves within $30 \mathrm{~min}$. We also found that the treatment of seedlings with Glu induced the expression of these genes but the induction of gene expression was much slower. Glu induced the expression of these genes from $12 \mathrm{~h}$ after treatment, with expressions peaking at $24 \mathrm{~h}$ (Supplementary Figs. S8 and S10). 
We next tested whether other amino acids with similar properties or structures to L-Glu (i.e., D-Glu, L-aspartate [Asp], and D-Asp) are capable of inducing PAMP-inducible genes. D-Glu, L-Asp, and D-Asp induced the expression of NHL1O but the expression levels were lower than the levels induced by L-Glu (Supplementary Fig. S11A). Similarly, D-Glu and D-Asp induced weaker expression of $C Y P 81 F 2$ than the level induced by L-Glu but L-Asp induced the expression of $C Y P 81 F 2$ to a similar extent as L-Glu. We tested whether treatment with $\mathrm{L}-\mathrm{His}$ induces the expression of the PAMP-inducible genes, because L-His induces resistance to $R$. solanacearum (Seo et al. 2016). L-His did not induce the expression of NHL1O or $C Y P 81 F 2$, suggesting that L-His may induce resistance by in a distinct manner (Supplementary Fig. S11B).

\section{SID2-mediated SA biosynthesis is dispensable for the Glu-induced expression \\ of PAMP-, DAMP-, and wound-inducible genes.}

Previous research suggested that SA signaling partially contributes to Glu-induced immunity in rice (Kadotani et al. 2016). Thus, we checked the role of SA signaling in the expression of Glu-inducible genes in Arabidopsis. We performed RNA-Seq analyses in ecotype Columbia (Col-0) and the SAdeficient mutant SA-induction defecient2 (sid2) at $48 \mathrm{~h}$ after Glu treatment (Supplementary Table S6). The MDS plot showed that Glu treatment resulted in different gene expression profiles in the Col- 0 and sid 2 plants, whereas urea treatment resulted in only slight differences between the two backgrounds (Supplementary Fig. S12A). Glu treatment induced 3,311 and 3,565 genes in Col-0 and sid2, respectively, when compared with urea treatment (Supplementary Fig. S12B to D; Supplementary Table S7). Of these, 2,773 genes were upregulated by Glu in both genotypes, showing a high degree of overlap. Most of the PAMP-, DAMP-, and wound-inducible genes were upregulated by Glu treatment in both Col-0 and sid2 plants (Supplementary Fig. S12B to D). Consistently, the PTI marker genes NHL10, CYP81F2, and FRK1, as well as the woundinducible genes $O P R 3, J A Z 5$, and ZAT12, were all induced to similar levels in the Col-0 and sid2 plants (Supplementary Fig. $\mathrm{S} 12 \mathrm{E}$ ). The results suggest that SA biosynthesis by SID2 is not required for Glu-induced expression of the PAMP-, DAMP-, and wound-inducible genes. This finding is also consistent with the fact that many genes commonly upregulated by three PAMPs (chitin, flg22, and elf26) and Glu are not SA responsive (Supplementary Fig. S13).

\section{Glu-inducible gene expression does not require known PAMP receptors or PTI regulators.}

To determine whether Glu activates the canonical PTI signaling pathways, we assessed the Glu-inducible expression of defense-related genes in Arabidopsis lines with single (cerkl) or double (efr fls2) mutations in PAMP receptors or double mutations (bakl-5 bkkl and bikl pbll) in PTI regulators. The flg22-, elf18-, and pep1-inducible responses are barely activated in the bakl-5 bkkl double mutant (Choi et al. 2016; Roux et al. 2011). Similarly, the bikl pbll double mutant shows reduced flg22inducible responses because it lacks the two receptor-like cytoplasmic kinases BOTRYTIS-INDUCED KINASE1 (BIK1) and PBS1-LIKE1 (PBL1), which are needed for the induction of flg22-triggered immunity (Kadota et al. 2014; Li et al. 2014; Liu et al. 2013). NHL10, OXI1, GAD4, AT2G04495 (which encodes a transmembrane protein), and $A T 3 G 13600$ (which encodes a calmodulin-binding family protein) are all Glu and PAMP inducible (Denoux et al. 2008; Ikeuchi et al. 2017; Jiang et al. 2017; Ross et al. 2014; Wan et al. 2008). We checked their expression by quantitative reverse-transcription PCR (RT-qPCR) in the mutants and found that all of these genes were expressed in all of the mutants (Fig. 5). The results indicate that the Gluinducible expression of these Glu- and PAMP-inducible genes does not require the PTI components tested.

\section{GLR3.3 and GLR3.6 contribute to the early expression of the Glu-inducible genes but are not required for their sustained expressions.}

To check the importance of GLR3.3 and GLR3.6 in Gluinducible defense signaling, we checked the time course of the Glu-inducible expression of OPR3, JAZ5, and NHL1O in Col-0 plants and a $g l r 3.3 a$ glr3.6a double mutant. Interestingly, the induction of each gene was delayed in the mutant at $12 \mathrm{~h}$ after Glu treatment but the sustained expression of each gene at 24 and $48 \mathrm{~h}$ was not affected (Fig. 6A to C). Similarly, there were no differences between Col- 0 and the glr3.3a glr3.6a double mutant in the Glu-inducible expression of NHL10, OXI1, GAD4, $A T 2 G 04495$, and AT3G13600 at $48 \mathrm{~h}$ after treatment (Supplementary Fig. S14). These results show that GLR3.3 and GLR3.6 play roles in the rapid induction of the Glu-inducible genes but are not required for their sustained expression. In addition, there were no differences between Col-0 and the glr3.3a glr3.6a double mutant in the sustained expression of $O P R 3$ and JAZ5 at
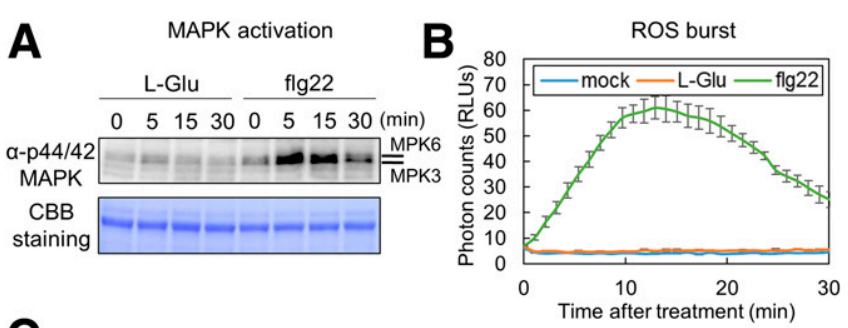

C
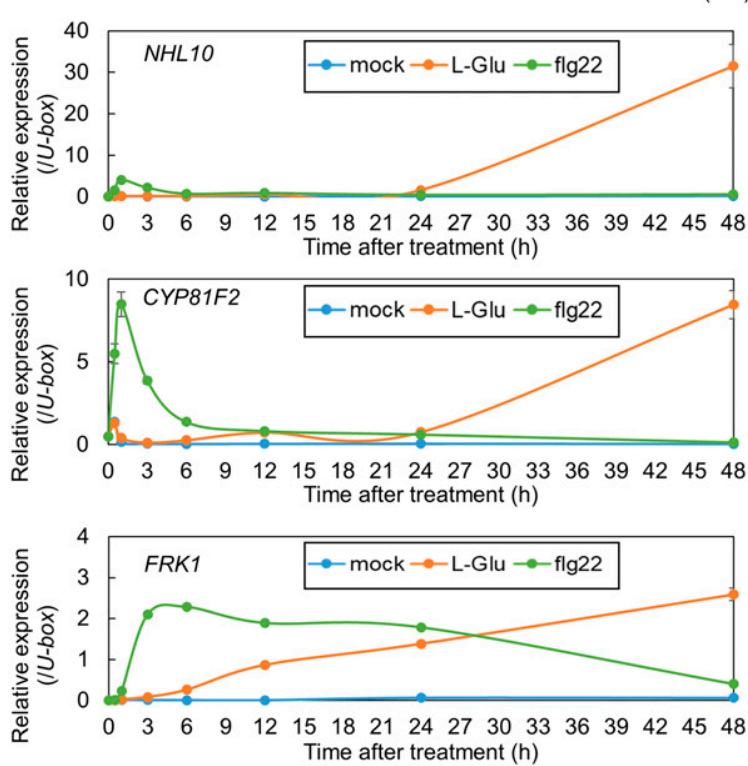

Fig. 4. Glutamate (Glu) does not induce detectable mitogen-activated protein kinase (MAPK) activation or reactive oxygen species (ROS) production but does induce the pattern-triggered immunity PTI marker genes NHL10, CYP81F2, and FRK1 in Arabidopsis. Glu induces these marker genes much more gradually than the pathogen-associated molecular pattern flg22. A, MAPK activation after L-Glu, flg22, or distilled water (mock) treatment of mature leaves. $\mathrm{CBB}=$ Coomassie Brilliant Blue. B, ROS production after $\mathrm{L}$-Glu, flg22, or distilled water (mock) treatment of mature leaves. C, Quantitative reverse-transcription PCR analyses of NHL10, CYP81F2, and FRK1 expression in seedlings treated with L-Glu, flg22, or distilled water (mock). The 14-day-old Arabidopsis seedlings were treated with $20 \mathrm{mM} \mathrm{L}$-Glu, $1 \mu \mathrm{M}$ flg22, or distilled water (mock) for $0.5,1,3,6,12$, 24 , or $48 \mathrm{~h}$. Relative transcript levels were calculated by normalization against the $U$-box transcript (At5g15400). Data for B and C are the means \pm standard error of three technical replicates. All experiments were repeated at least three times with similar results. 
$48 \mathrm{~h}$ after treatment with various doses of Glu (Fig. 6D and E). This suggests that GLR3.3 and GLR3.6 are not required for the sustained expression of $O P R 3$ and JAZ5.

Glu activates the expression of PAMP-, DAMP-, and $\mathrm{SA}$-inducible genes and primes chitin-inducible responses in systemic tissues.

Because Glu treatment induced systemic resistance against pathogens (Fig. 1), we checked the expression of genes in leaves after treatment of roots with Glu. We found that, by $72 \mathrm{~h}$ posttreatment, Glu had induced the expression of the PAMP- and DAMP-inducible genes NHL10 and CYP81F2, the JA- and

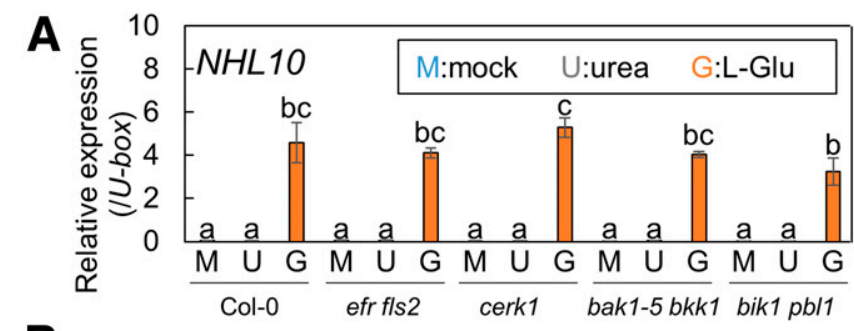

B
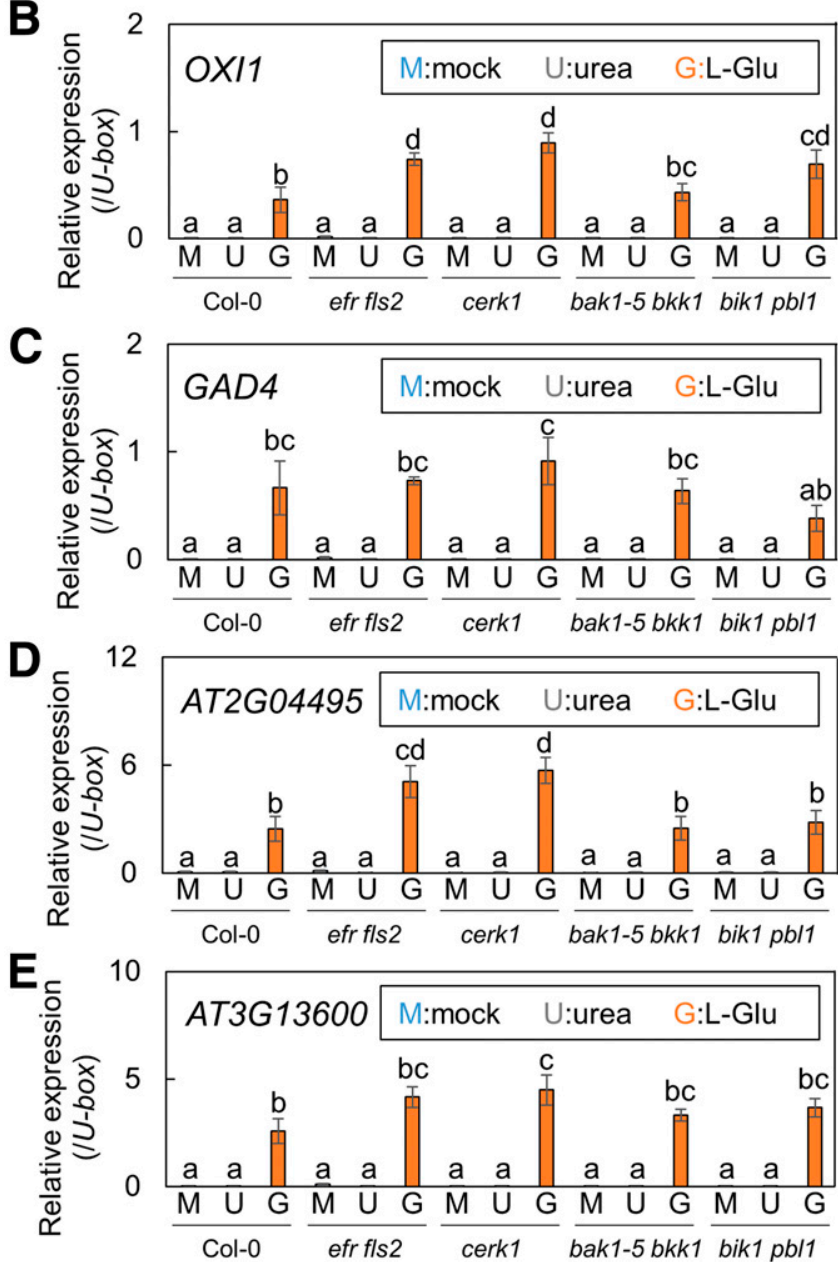

Fig. 5. Glutamate (Glu) activates Glu- and pathogen-associated molecular pattern (PAMP)-inducible genes in Arabidopsis plants with mutations in the genes encoding PAMP receptors and pattern-triggered immunity regulators. Quantitative reverse-transcription PCR analyses of the genes A, NHL10; B, OXI1; C, GAD4; D, AT2G04495; and E, AT3G13600 in Col-0 and the mutants efr fls2, cerk1, bakl-5 bkk1, and bikl pbll. The 14-day-old seedlings were treated with $20 \mathrm{mM}$ urea, $20 \mathrm{mM} \mathrm{L-Glu}$, or distilled water (mock) for $48 \mathrm{~h}$. Relative transcript levels were calculated by normalization against the $U$-box transcript (At5g15400). Data are the means \pm standard error of three biological replicates. Different letters indicate significantly different values at $P$ value $\leq 0.05$ (one-way analysis of variance, Tukey's post hoc test). wound-inducible gene JAZ5, and the SA-inducible genes PRI, enhanced disease susceptibility 1 (EDS1), and phytoalexin deficient 4 (PAD4) (Fig. 7A and B). We also checked the expression of the PAMP receptor genes $L Y K 5, C E R K 1$, and FLS2 in leaves after treatment of roots with Glu. Interestingly, the expression of the chitin receptor gene $L Y K 5$ was upregulated, whereas the expression levels of CERK1 and FLS2 were barely affected by treatment with Glu (Fig. 7C). This implies that Glu might prime chitin-induced responses by increasing the amount of the chitin receptor. Indeed, the treatment of roots with Glu prolonged the chitin-induced activation of MPK3 and enhanced ROS production in leaves (Fig. 7D and E). In contrast to Glu, SA and BTH can each activate $F L S 2$ expression, induce the accumulation of the FLS2 protein, and prime the flg22-mediated responses, including an ROS burst (Tateda et al. 2014; Yi et al. 2014) (Supplementary Fig. S15). These results suggest that the Glu-mediated priming of chitin responses is distinct from SA signaling.

\section{DISCUSSION}

Previous research showed that Glu induces resistance against fungi in rice by SA-dependent and SA-independent mechanisms

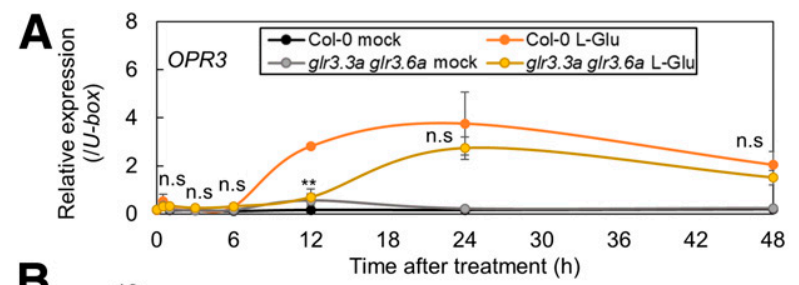

B
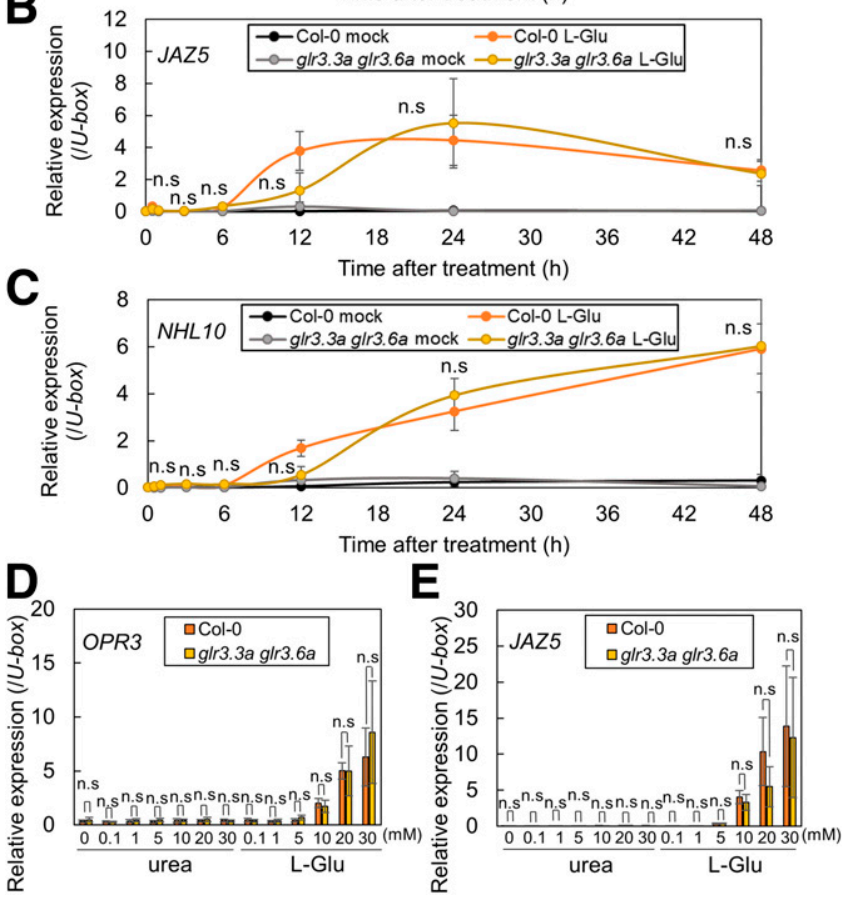

Fig. 6. Expression patterns of OPR3, JAZ5, and NHL1O in 14-day-old seedlings of Col-0 and the glr3.3a glr3.6a double mutant after treatment with glutamate (Glu). Expression levels of A, OPR3; B, JAZ5; and C, NHL10 are shown after treatment of the seedlings with $20 \mathrm{mM}$ L-Glu or distilled water (mock) for $0.5,1,3,6,12,24$, or $48 \mathrm{~h}$. Effects of Glu concentration on the expression of $\mathbf{D}$, OPR3 and $\mathbf{E}$, JAZ5 in 14-day-old Col-0 and glr3.3a glr3.6a seedlings treated with different concentrations of urea or L-Glu $(0.1,1,5,10$, 20 , or $30 \mathrm{mM}$ ) for $48 \mathrm{~h}$. Relative transcript levels were calculated by normalization against the $U$-box transcript (At5g15400). Data are means \pm standard error of three technical replicates. Black asterisks indicate a significant difference based on the Student's $t$ test (** indicate $P$ value $\leq 0.01$; n.s. $=$ not significant). Experiments were performed three times with similar results. 

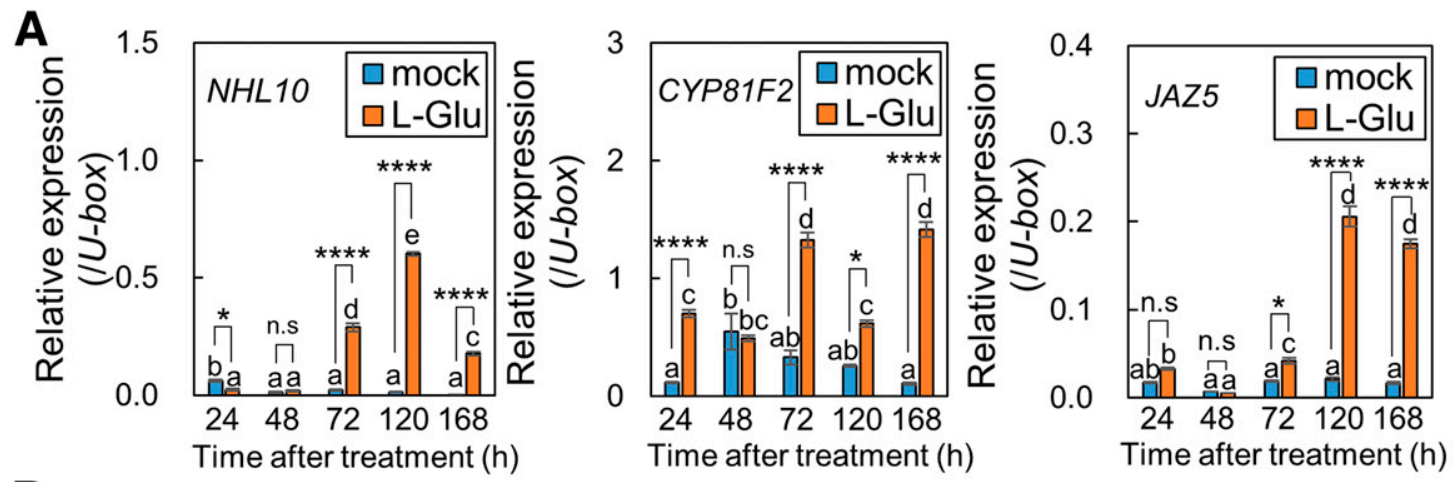

B
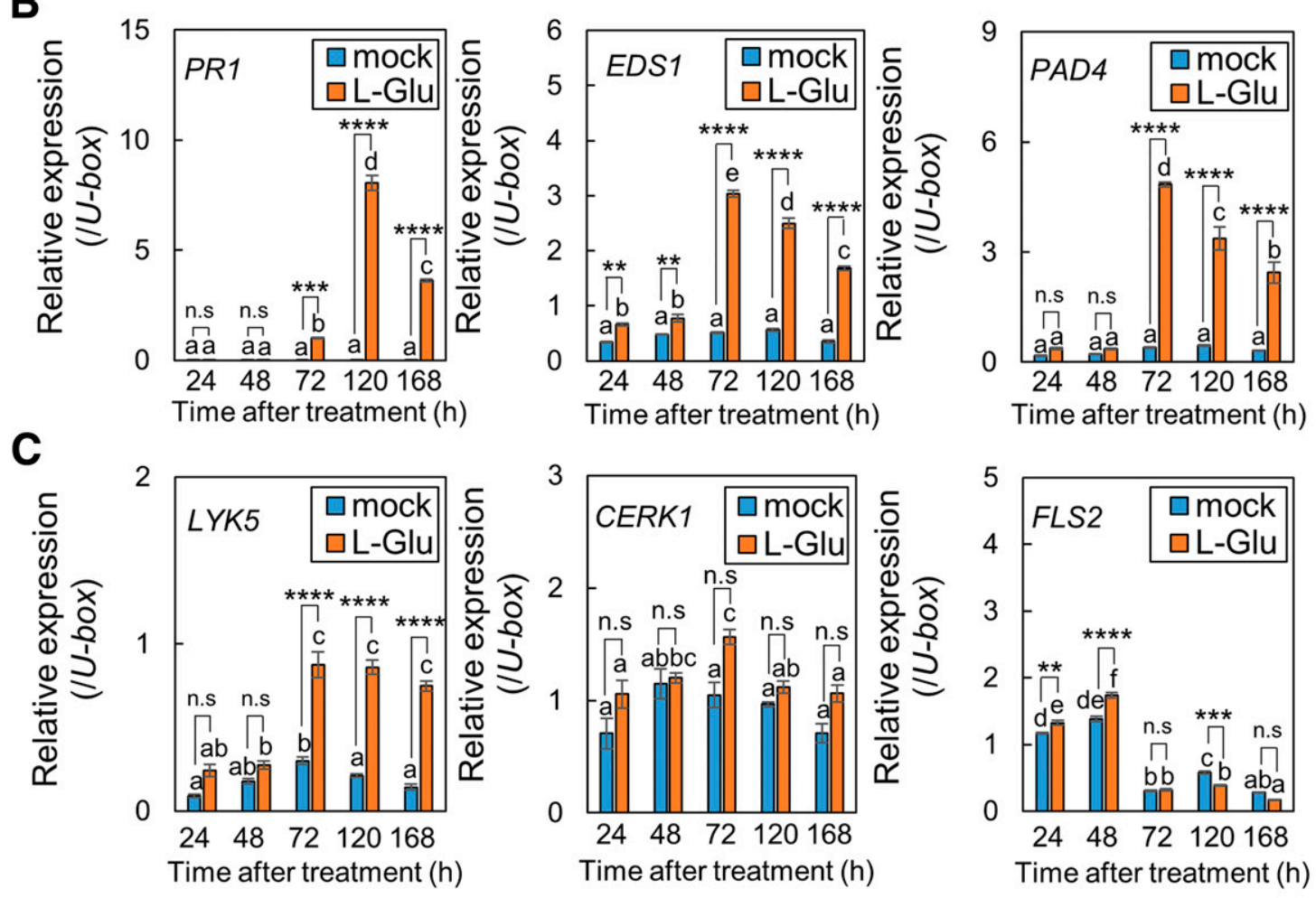

\section{Chitin-induced MAPK activation}
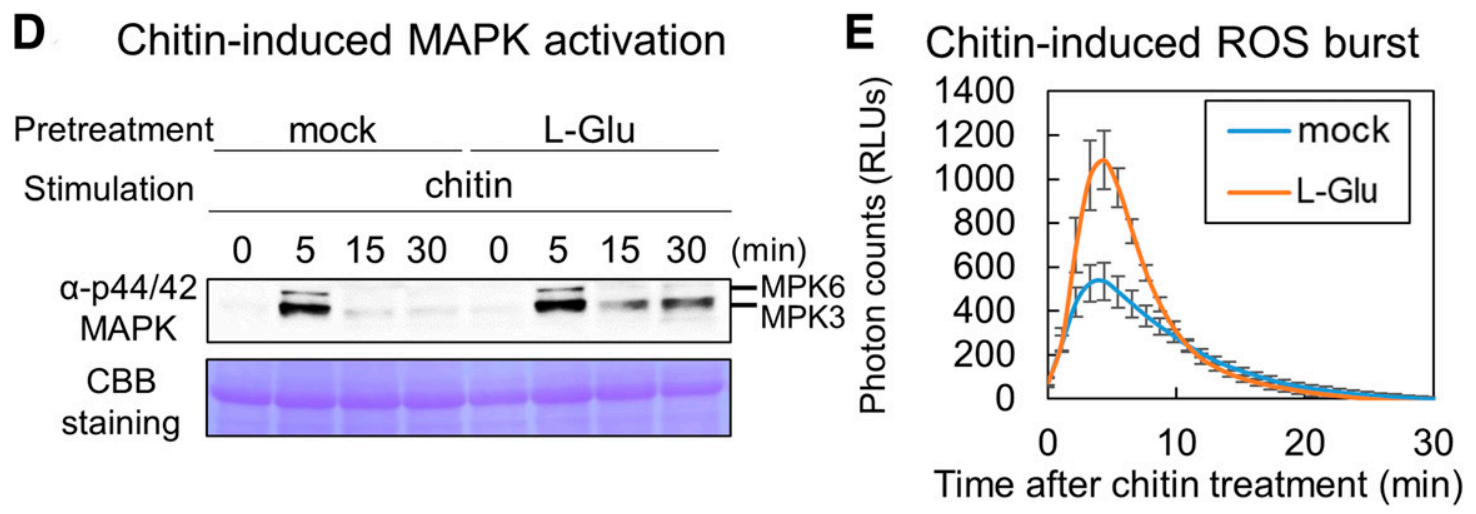

Fig. 7. Glutamate (Glu) primes chitin-triggered immune responses. Quantitative reverse-transcription PCR analyses of A, NHL10, CYP81F2, and JAZ5; B, PR1, EDS1, and PAD4; and C, LYK5, CERK1, and FLS2 in mature Arabidopsis leaves after treatment with L-Glu or distilled water (mock). Roots of 6-weekold plants were pretreated with $20 \mathrm{mM} \mathrm{L}-$ Glu or distilled water for $24,48,72,120$, or $168 \mathrm{~h}$. Relative transcript levels were calculated by normalization against the $U$-box transcript $(A t 5 g 15400)$. Data are the means \pm standard error of three technical replicates. Different letters indicate significant differences based on a one-way analysis of variance with Tukey's post hoc test $(P$ value $\leq 0.05)$ and black asterisks indicate significant differences based on the Student's $t$ test $(*, * *$, $* * *$, and $* * * *$ indicate $P$ value $\leq 0.05,0.01,0.001$, and 0.001 , respectively; n.s. $=$ not significant). Pretreatment with Glu D, prolongs chitin-induced MPK3 activation and $\mathbf{E}$, enhances chitin-inducible reactive oxygen species (ROS) production. The 6-week-old Arabidopsis plants were pretreated with $20 \mathrm{mM}$ L-Glu or distilled water (mock). Entire pots were submerged in these solutions for $48 \mathrm{~h}$. Then, leaf discs were collected to analyze chitin-induced mitogen-activated protein kinase (MAPK) activation and ROS production. $\mathrm{CBB}=$ Coomassie Brilliant Blue. Data for $\mathrm{E}$ are the means \pm standard error of three technical replicates. All experiments were performed three times with similar results. 
(Kadotani et al. 2016). However, the mechanism of Glu-inducible SA-independent immunity was unknown. In this study, we investigated the mechanisms of Glu-inducible disease resistance using Arabidopsis. We performed extensive gene expression analyses using seedlings and soil-grown plants, revealing that exogenous treatment with Glu not only induces the expression of SA-inducible genes but also strongly induces expression of PAMP-, DAMP-, and wound-inducible genes in the seedlings treated with Glu and in the systemic tissues after Glu treatment in the roots (Figs. 2B to E, 3, and 7A to C; Table 1). We also showed that SID2-mediated SA biosynthesis is not required for the activation of PAMP- and DAMP-inducible genes by Glu (Supplementary Fig. S12). Because PAMP treatment triggers SA biosynthesis and expression of SA-responsive genes (Mishina and Zeier 2007; Tsuda et al. 2008), Glu-mediated induction of PTI may activate an SA-mediated signaling pathway. Both the PTIsignaling pathway and the SA-mediated signaling pathway would then contribute to resistance against pathogens. Note that it is possible that Glu directly affects pathogens. We found that Glu might serve as a nutrient source for the bacterium and enhanced the growth of $P$. syringae pv. tomato DC3000 in in vitro culture (Supplementary Fig. S1B). In addition, the presence of nutrients can change the cellular entry mode of pathogens. For example, exogenous treatment with glucose or sucrose changes the cellular entry mode of C. gloeosporioides and enhances the virulence to Arabidopsis mutants lacking the genes encoding penetration 2 (PEN2) myrosinase and other enzymes required for the biosynthesis of PEN2 substrate, 4-methoxynidol-3-ylmethylglucosinolates (Hiruma et al. 2010). Thus, it would be important to know the direct effect of Glu on pathogens before using Glu as PRI.

Although Glu strongly activates the expression of PAMPand DAMP-inducible genes, the mechanism by which Glu activates immunity appears to be different from the mechanism triggered by PAMPs or DAMPs. First, Glu induces expression of the PTI marker genes more gradually and for much longer periods than flg22 (Fig. 4C). Second, expression of the Gluinduced genes requires a high concentration of Glu (higher than $10 \mathrm{mM}$ ), whereas known PAMPs and DAMPs activate responses at the range from several hundred nanomolar to several micromolar concentrations (Fig. 6D and E; Supplementary Fig. S9). Third, Glu does not induce strong activation of MAPKs or ROS production, which are typical signaling events induced by most PAMPs and DAMPs. Finally, Glu-induced gene expression does not require important signaling components of PTI such as BAK1, BKK1, BIK1, PBL1, and CERK1. These results suggest that Glu does not work like a PAMP or DAMP but, instead, induces expression of the PAMP- and DAMP-inducible genes in a previously uncharacterized manner.

Previous work showed that Glu induces $\left[\mathrm{Ca}^{2+}\right]_{\mathrm{cyt}}$ changes and plasma membrane depolarization within 10 to $30 \mathrm{~s}$, and that GLR3.3 plays important roles in these responses (Qi et al. 2006). Similarly, Glu was recently shown to function as a wound signal that triggers long-distance $\mathrm{Ca}^{2+}$-based defenses in plants. The drop application of 50 to $100 \mathrm{mM} \mathrm{L-Glu}$ to precut leaves caused GLR3.3- and GLR3.6-dependent changes in the $\left[\mathrm{Ca}^{2+}\right]_{\text {cyt }}$ and induction of the wound- and JA-inducible genes OPR3, JAZ5, and JAZ7 (Toyota et al. 2018). Moreover, GLR3.3 and GLR3.6 are required for wound-induced changes in the membrane potential, triggering the expression of JA-responsive genes in distal leaves (Mousavi et al. 2013). On the other hand, high concentrations of Glu may also induce GLR3.3-independent pathways. Indeed, high concentrations of Glu induce plasma membrane depolarization even in the glr3.3 mutant, while the low concentration Glu responses require GLR3.3 (Qi et al. 2006). These results suggest that Glu activates both GLR3.3-dependent and independent pathways, depending on its concentration. We also found that the early induction of OPR3,JAZ5, and NHL1O by Glu requires GLR3.3 and GLR3.6 (Fig. 6A to C) whereas the sustained induction of OPR3, JAZ5, NHL10, OXI1, GAD4, $A T 2 G 04495$, and AT3G13600 does not (Fig. 6A to E; Supplementary Fig. S14). Qi et al. (2006) hypothesized that the GLR3.3independent membrane depolarization involves an $\mathrm{H}^{+}$-coupled amino acid symport (Fischer et al. 1998), because changing the external $\mathrm{pH}$ from 5.7 to 7.7 abolishes membrane depolarization. $\mathrm{H}^{+}$-coupled amino acid symporters have broad substrate specificity and are able to transport similar amino acids (Fischer et al. 1995). This may explain why not only Glu but also L-Asp, D-Glu, and D-Asp are able to induce the expression of PTI marker genes (Supplementary Fig. S11). Alternatively, the high concentrations of Glu may activate other uncharacterized GLRs that may have weak sensitivities to Glu. In any case, both the GLR3.3- and GLR3.6-dependent and -independent signaling pathways are likely to contribute to Glu-induced expression of PAMP- and DAMP-inducible genes and immunity against pathogens.

In addition to Glu-induced immunity, GLRs, especially GLR3.3, may also be involved in PTI signaling. Pharmacological studies showed that GLRs are involved in $\left[\mathrm{Ca}^{2+}\right]_{\mathrm{cyt}}$ changes and nitric oxide (NO) production in tobacco in response to cryptogein, a proteinaceous PAMP derived from Phytophthora cryptogea (Vatsa et al. 2011). Similarly, GLRs are partially involved in $\left[\mathrm{Ca}^{2+}\right]_{\text {cyt }}$ changes, NO production, ROS production, and expression of the defense-related genes in response to OGs in Arabidopsis (Manzoor et al. 2013). Moreover, GLRs were shown to be involved in the initiation of flg22-, elf18-, and chitin-triggered MAPK activation and expression of defense-related genes (Kwaaitaal et al. 2011). Among GLRs, GLR3.3 is required for the resistance in Arabidopsis against $P$. syringae pv. tomato DC3000 and Hyaloperonospora arabidopsidis but not for the resistance against B. cinerea (Li et al. 2013: Manzoor et al. 2013). These results may imply that Glu- or GLR3.3-mediated signaling is activated during pathogen infection and is involved in immunity.

Previous research showed that the concentrations of endogenous Glu are approximately 2 to $4 \mathrm{mM}$ in leaves and 16 to $50 \mathrm{mM}$ in phloem sap (Hunt et al. 2010; Sato and Yanagisawa 2014; Zhu et al. 2005). Moreover, Glu concentrations at leaf damage sites can reach levels of up to approximately $50 \mathrm{mM}$ (Toyota et al. 2018), and infection by an avirulent bacterial pathogen increases the concentration of Glu in tobacco leaves (Gupta et al. 2013). These results suggest that wounding and perhaps avirulent pathogen infection can result in the release of sufficient amounts of Glu to activate the expression of PAMP-, DAMP-, and wound-inducible genes. However, the exogenous application of Glu to intact seedlings induces very gradual expression of defense-related genes. Similarly, Glu treatment to the roots of mature plants also induces very gradual expression of defense-related genes in systemic tissues. It is possible that additional signals generated from tissue damage such as wounding signals and wound-induced electric signals are required to speed up the Glu-induced expression of defenserelated genes (Mousavi et al. 2013: Toyota et al. 2018). This may explain why the drop application of 50 to $100 \mathrm{mM}$ Glu to precut Arabidopsis leaves induced rapid and systemic expression of OPR3, JAZ5, and JAZ7 (Toyota et al. 2018). It is also possible that the precutting allowed easy access of the Glu to the leaf interior, resulting in the rapid induction of defenserelated genes.

Amino acids are used commercially as fertilizers for various crops to accelerate their growth and development (Popko et al. 2018). Glu is widely used in the food industry as a seasoning, and the safety of Glu as a food additive has been approved 
by food safety authorities in many countries, including the European Commission's Scientific Committee on Food and the U.S. Food and Drug Administration (Walker and Lupien 2000). Importantly, Glu treatment at the concentration that is effective for inducing immunity and priming does not affect plant growth (Supplementary Fig. S16). Therefore, Glu could be an ideal PRI, and we believe that Glu has the potential to contribute to sustainable disease control in agriculture.

\section{MATERIALS AND METHODS}

\section{Plant materials and growth conditions.}

Seed of Arabidopsis thaliana Col-0 and the T-DNA insertion mutants efr fls2 (Zipfel et al. 2004, 2006), cerkl (GiménezIbañez, et al. 2009), bakl-5 bkkl (Schwessinger et al. 2011), bikl pbll (Zhang et al. 2010), and glr3.3a glr3.6a (Mousavi et al. 2013) were sown on soil or half-strength MurashigeSkoog medium containing $1 \%$ sucrose. The seed were coldtreated for 2 days to break seed dormancy. Plants for pathogen testing were transferred to a growth chamber and kept under short-day photoperiods ( $8 \mathrm{~h}$ of light and $16 \mathrm{~h}$ of darkness) at $23^{\circ} \mathrm{C}$. Liquid-cultured seedlings were grown under continuous light at $23^{\circ} \mathrm{C}$.

\section{In vitro bacterial culture.}

A starting culture of $P$. syringae pv. tomato DC3000 was grown in liquid Luria-Bertani (LB) (supplemented with rifampicin at $100 \mu \mathrm{g} / \mathrm{ml}$ ) overnight at $28^{\circ} \mathrm{C}$. The following day, the starting culture was used to seed new cultures $\left(20 \mathrm{mM} \mathrm{MgCl}_{2}\right.$, with or without $20 \mathrm{mM} \mathrm{L-Glu}$ ) to an optical density at $600 \mathrm{~nm}$ $\left(\mathrm{OD}_{600}\right)=0.2$. These cultures were allowed to grow at $28^{\circ} \mathrm{C}$ with shaking, and $\mathrm{OD}_{600}$ values were measured at 24,48 , and $72 \mathrm{~h}$.

\section{L-Glu pretreatments and pathogen challenges.}

Soil-grown Arabidopsis plants (4 to 6 weeks old) were treated with $20 \mathrm{mM} \mathrm{L-Glu}$ or distilled water (mock). For the experiments shown in Figure 1A and Supplementary Fig. S1A, pretreatment of leaves was carried out as described by Zipfel et al. (2004) with little modification. Three mature Arabidopsis leaves were syringe inoculated with each of these solutions for $48 \mathrm{~h}$ before pathogen inoculation. For the experiments shown in Figure $1 \mathrm{~B}$ and $\mathrm{C}$, the pretreatment of roots was carried out as described by Seo et al. (2016). Whole pots were submerged in these solutions for $48 \mathrm{~h}$, with the tops of the plants left in the air, before pathogen inoculation.

P. syringae pv. tomato DC3000 infection assays were performed as described by Zipfel et al. (2004). Bacteria were propagated in LB media containing rifampicin at $100 \mu \mathrm{g} / \mathrm{ml}$. Leaves of 5- to 6-week-old Arabidopsis plants (3 leaves/plant) were syringe infiltrated with $10 \mathrm{mM} \mathrm{MgCl}_{2}$ solution containing bacteria at a concentration of $1.0 \times 10^{5} \mathrm{CFU} / \mathrm{ml}$. Three days after bacterial infiltration, leaves were harvested and bacteria were quantified as described previously (Kim et al. 2005).

C. higginsianum infection assays were carried out as described by Hiruma and Saijo $(2016 a, b)$ with a slight modification. Conidia ( 7 to 10 days old) of $C$. higginsianum were grown on potato dextrose agar under $12 \mathrm{~h}$ of near-UV blue light and $12 \mathrm{~h}$ of darkness at $25^{\circ} \mathrm{C}$. Conidia were washed three times with distilled water, and their numbers were counted using a Bright-Line Hemocytometer (Hausser Scientific). Droplets (5 $\mu$ l each) containing $5.0 \times 10^{6}$ conidia $/ \mathrm{ml}$ were spotted on leaves of 3-week-old Arabidopsis plants. To maintain high humidity, infected plants were watered and sealed in airtight plant trays. At 7 to 9 days postinfection, macroscopic symptoms were assessed by measuring the lesion sizes in the $\mathrm{X}$ - and Y-axis directions using Fiji software (Schindelin et al. 2012).

\section{RNA-Seq and differential gene expression analyses.}

Arabidopsis Col-0 and sid2 seedlings were grown in liquid half-strength Murashige-Skoog medium containing 1\% sucrose. Seedlings (14 days old) were transferred to distilled water 1 day prior to treatment with $20 \mathrm{mM}$ urea, $20 \mathrm{mM} \mathrm{L}-\mathrm{Glu}$, or $1 \mathrm{mM} \mathrm{SA}$ for $6,12,24$, and $48 \mathrm{~h}$, with three biological repeats of each treatment. Transcript levels were then analyzed by RNA-Seq. Urea was used to determine whether an increased nitrogen supply would affect transcript levels.

RNA-Seq library preparation was carried out using a highthroughput RNA-Seq method (Kumar et al. 2012). The 50-bp single-end reads were sequenced on an Illumina Hiseq 4000 platform. The FASTX toolkit 0.0.13.2 (Hannonlab) was used for quality filtering. The first $6 \mathrm{bp}$ were trimmed from the reads to remove barcode sequences. Low-quality nucleotides (quality scores < 30) were removed from the $3^{\prime}$ ends and short reads ( $<39$ bp) and reads showing at least $95 \%$ of nucleotides with quality scores $<20$ were removed. Filtered reads were mapped to the Arabidopsis genome TAIR10.30 by tophat v2.1.0 (Center for Computational Biology at Johns Hopkins University) (Trapnell et al. 2009). Read counts were extracted by HTSeq, version 0.6.0 (Anders et al. 2015). The downstream bioinformatic analysis was performed as described previously (Ichihashi et al. 2018). The trimmed mean of $\mathrm{M}$ values (TMM) normalized reads (Supplementary Tables S1 and S6), derived using the Bioconductor package edgeR 3.22.3 (Robinson et al. 2010), were used to create MDS plots and perform the differentially expressed gene analyses. MDS plots were made using the R stats package cmdscale. The differentially expressed gene data (FDR $\leq 0.01$ ) were extracted using edgeR (McCarthy et al. 2012; Robinson et al. 2010). The gene set enrichment analysis was performed using the two-tailed Fisher's exact test in the R program, version 3.5.0. Sequencing reads and the TMM-normalized counts of the RNASeq data were deposited in NCBI's Gene Expression Omnibus database under accession number GSE123622.

\section{PCA with SOM clustering.}

TMM-normalized counts were used to perform SOM clustering as described previously (Chitwood et al. 2013; Ranjan et al. 2014). After selecting differentially expressed genes within the top $25 \%$ of the coefficient of variation across samples, scaled expression values were used for multilevel threeby-four hexagonal SOM clustering (Wehrens and Buydens 2007). One hundred training interactions were used during the clustering, over which the $\alpha$ learning rate was decreased from 0.0076 to 0.0056 . The final assignment of genes to winning units formed the basis of the gene clusters. The results of SOM clustering were visualized in a PCA space where PC values were calculated based on gene expression across samples using the R stats package prcomp (Supplementary Fig. S2).

\section{GO term enrichment analyses.}

GO term enrichment analyses were performed using PANTHER (Thomas et al. 2003) from the Gene Ontology Consortium (Ashburner et al. 2000; The Gene Ontology Consortium 2017).

\section{Venn diagram analyses.}

Venn diagrams were constructed using VENNY 2.1. The Gene IDs of the wound-inducible genes (FDR $\leq 0.05)$ (Ikeuchi et al. 2017), OG-inducible genes (fold change $\geq 2, P$ value $\leq$ 0.01) (Denoux et al. 2008), pep2-inducible genes (fold change $\geq 2, q \leq 0.05$ ) (Ross et al. 2014), eATP-inducible genes (fold change $\geq 2$, FDR $\leq 0.05$ ) (Choi et al. 2014), BABA-inducible genes (fold change $\geq 2, P$ value $\leq 0.35 \%$ ) (Zimmerli et al. 2008), and the genes induced by all three of the PAMPs (chitin, flg22, and elf26) (fold change $\geq 2$ ) (Wan et al. 2008) are summarized in Supplementary Table S9. 


\section{RT-qPCR analyses.}

RT-qPCR analyses were performed as described previously (Kadota et al. 2019). Two-week-old Arabidopsis seedlings were treated with 0.1 to $20 \mathrm{mM}$ urea (Wako), 0.1 to $20 \mathrm{mM} \mathrm{L-Glu}$ (Wako), 20 mM D-Glu (Wako), 20 mM L-Asp (Wako), or $20 \mathrm{mM}$ D-Asp (Wako) as described in the figure legends. All treatments were adjusted to $\mathrm{pH}=5.8$. Total RNA was extracted from the seedlings using the RNeasy Plant Mini Kit (Qiagen) according to the manufacturer's instructions. First-strand cDNA was synthesized using a ReverTra Ace qPCR RT Kit (Toyobo) with random primers, and RT-qPCR was performed using the Thunderbird SYBR qPCR Mix (Toyobo) in a Stratagene $m x 3000 p$ real-time thermal cycler (Agilent). The relative transcript levels were calculated using the standard curve method followed by normalization against the $U$-box housekeeping gene (At5g15400). All primers used for RT-qPCR are listed in Supplementary Table S8.

\section{MAPK activation assays.}

For the experiment shown in Figure 7, 6-week-old soil-grown Arabidopsis plants were treated with $20 \mathrm{mM}$ L-Glu or distilled water (mock). Four whole pots were submerged in each of these solutions for $48 \mathrm{~h}$; then, four leaf disks ( $8 \mathrm{~mm}$ in diameter) were excised from mature leaves of each plant and floated overnight on sterile water. The following day, the discs were treated with $10 \mu \mathrm{M}$ chitin for $0,5,15$, or $30 \mathrm{~min}$ (four discs per treatment), then immediately frozen in liquid nitrogen and stored at $-80^{\circ} \mathrm{C}$. For the experiment shown in Figure 4, four leaf discs $(8 \mathrm{~mm}$ in diameter) from each of four 4- to 6-week-old plants were floated overnight on sterile water. The following day, the discs were treated with $20 \mathrm{mM}$ L-Glu ( $\mathrm{pH}=5.8), 1 \mu \mathrm{M}$ flg22, or distilled water for $0,5,15$, or $30 \mathrm{~min}$ (four discs per treatment), then immediately frozen in liquid nitrogen and stored at $-80^{\circ} \mathrm{C}$. Samples were ground to a fine powder with zirconia beads using FastPrep-24 (MPBio). Proteins were extracted in a buffer (50 mM Tris- $\mathrm{HCl}$ [pH = 7.5], $150 \mathrm{mM} \mathrm{NaCl}, 10 \%$ glycerol, $2 \mathrm{mM}$ EDTA, $5 \mathrm{mM}$ dithiothreitol, $1 \times$ EDTA-free Complete Protease Inhibitor Cocktail [Roche], 0.1\% IGEPAL CA630, $0.5 \mathrm{mM}$ phenylmethylsulfonyl fluoride, $1 \mathrm{mM} \mathrm{Na} 2 \mathrm{MoO}_{4}, 1 \mathrm{mM}$ $\mathrm{NaF}, 0.5 \mathrm{mM} \mathrm{Na}_{3} \mathrm{VO}_{4}$, and $20 \mathrm{mM} \beta$-glycerophosphate) that was added at a rate of $2 \mathrm{ml} / \mathrm{g}$ of powdered tissue. The mixture was centrifuged at $16,000 \times \mathrm{g}$ and the protein concentration in the supernatant was measured using a Bio-Rad protein assay (BioRad Laboratories). Total proteins ( 15 or $30 \mu \mathrm{g}$ ) were separated by sodium dodecyl sulfate polyacrylamide gel electrophoresis and blotted onto a polyvinylidene diflouride membrane using the Transblot machine according to the manufacturer's instructions (Bio-Rad Laboratories). The membrane was blocked overnight at $4{ }^{\circ} \mathrm{C}$ in a solution of $5 \%$ (wt/vol) skim milk (Wako) in Trisbuffered saline with $0.05 \%$ (vol/vol) Tween 20. Phosphorylated MAPKs were detected using an antiphospho-p44/42 MAPK (Erk1/2) (Thr202/Tyr204) (D13.14.4E) rabbit monoclonal antibody (1:2,000) (Cell Signaling Technology) for $1 \mathrm{~h}$ at room temperature, followed by incubation with antirabbit immunoglobulin $\mathrm{G}$ horseradish peroxidase (HRP)-conjugated secondary antibodies $(1: 10,000)$ (Roche) for $1 \mathrm{~h}$ at room temperature in a solution of $5 \%(\mathrm{wt} / \mathrm{vol})$ skim milk (Wako) in Tris-buffered saline with $0.05 \%$ (vol/vol) Tween 20 . The HRP-conjugated antibodies were detected using Super Signal West Femto Maximum Sensitivity Substrate (Thermo Fisher Scientific) with an LAS 4000 system (GE Healthcare). Duplicate membranes were stained with Coomassie Brilliant Blue to verify equal loading.

\section{ROS burst assays.}

ROS burst assays were carried out as described previously (Kadota et al. 2014). For the experiments shown in Figure 7 and Supplementary Figure S15, six 4- to 6-week-old soil-grown
Arabidopsis plants were treated with $20 \mathrm{mM} \mathrm{L-Glu}, 20 \mathrm{mM}$ urea, $1 \mathrm{mM}$ SA, or distilled water (mock). Whole pots were submerged in these solutions for $48 \mathrm{~h}$; then, eight leaf discs (4 $\mathrm{mm}$ in diameter) were removed from mature leaves of each plant using a cork borer and floated overnight on sterile water, with three replicates of eight discs. The following day, the water was replaced with a solution containing the chemiluminescent probe L-012 (1 $\mu \mathrm{M})$ (Wako), HRP at $20 \mu \mathrm{g} / \mathrm{ml}$ (Sigma-Aldrich), and $10 \mu \mathrm{M}$ chitin (Elicityl). Luminescence was captured over 30 min using a Tristar ${ }^{2}$ multimode reader (Berthold Technologies). For the experiment shown in Figure 4, 12 leaf discs (4 $\mathrm{mm}$ in diameter) from each of six 4- to 6-week-old plants were floated overnight on sterile water. The following day, the water was replaced with a solution containing the chemiluminescent probe L-012 with HRP at $20 \mu \mathrm{g} / \mathrm{ml}$ and $20 \mathrm{mM}$ L-Glu ( $\mathrm{pH}=5.8), 1 \mu \mathrm{M}$ flg22 (MBL), or distilled water (eight discs per treatment). Each treatment was replicated three times and luminescence was captured as described above. For the experiment shown in Supplementary Fig. S6, 24 7-day-old Arabidopsis seedlings were kept overnight in sterile water. The following day, the water was replaced with a solution containing the chemiluminescent probe L-012 with HRP at $20 \mu \mathrm{g} / \mathrm{ml}$ and $20 \mathrm{mM}$ L-Glu ( $\mathrm{pH}=5.8), 1 \mu \mathrm{M}$ flg22 (MBL), or distilled water (eight seedlings per treatment). Luminescence was captured as described above.

\section{ACKNOWLEDGMENTS}

We thank E. E. Farmer for providing the glr3.3a glr3.6a double mutant, C. Zipfel for the bak1-5 bkk1 double mutant, J.-M. Zhou for the bik1 pbll double mutant, and all members of K. Shirasu's lab for their intensive discussions; A. Tsushima, A. Ueno, N. Watanabe, Y. Nagai, K. Hori, and M. Kouzai for their support; and A. Laohavisit, K. Sato, M. R. Fishman, N. A. Espinas, P. Gan, and B. P. M. Ngou for critically reading the manuscript.

\section{AUTHOR-RECOMMENDED INTERNET RESOURCES}

FASTX toolkit: http://hannonlab.cshl.edu/fastx_toolkit The Gene Ontology Consortium: http://geneontology.org HTSeq, version 0.6.0: https://htseq.readthedocs.io/en/release_0.11.1 PANTHER: http://www.pantherdb.org tophat v2.1.0: https://ccb.jhu.edu/software/tophat/index.shtml VENNY 2.1: https://bioinfogp.cnb.csic.es/tools/venny

\section{LITERATURE CITED}

Alexandersson, E., Mulugeta, T., Lankinen, Å., Liljeroth, E., and Andreasson, E. 2016. Plant resistance inducers against pathogens in Solanaceae species-From molecular mechanisms to field application. Int. J. Mol. Sci. 17:1673.

Anders, S., Pyl, P. T., and Huber, W. 2015. HTSeq-A Python framework to work with high-throughput sequencing data. Bioinformatics 31:166-169.

Ashburner, M., Ball, C. A., Blake, J. A., Botstein, D., Butler, H., Cherry, J. M., Davis, A. P., Dolinski, K., Dwight, S. S., Eppig, J. T., Harris, M. A., Hill, D. P., Issel-Tarver, L., Kasarskis, A., Lewis, S., Matese, J. C., Richardson, J. E., Ringwald, M., Rubin, G. M., and Sherlock, G. 2000. Gene Ontology: Tool for the unification of biology. Nat. Genet. 25: 25-29.

Benedetti, M., Pontiggia, D., Raggi, S., Cheng, Z., Scaloni, F., Ferrari, S., Ausubel, F. M., Cervone, F., and De Lorenzo, G. 2015. Plant immunity triggered by engineered in vivo release of oligogalacturonides, damageassociated molecular patterns. Proc. Natl. Acad. Sci. U.S.A. 112: 5533-5538.

Boutrot, F., and Zipfel, C. 2017. Function, discovery, and exploitation of plant pattern recognition receptors for broad-spectrum disease resistance. Annu. Rev. Phytopathol. 55:257-286.

Brutus, A., Sicilia, F., Macone, A., Cervone, F., and De Lorenzo, G. 2010. A domain swap approach reveals a role of the plant wall-associated kinase 1 (WAK1) as a receptor of oligogalacturonides. Proc. Natl. Acad. Sci. U.S.A. 107:9452-9457.

Cao, Y., Liang, Y., Tanaka, K., Nguyen, C. T., Jedrzejczak, R. P., Joachimiak, A., and Stacey, G. 2014. The kinase LYK5 is a major chitin 
receptor in Arabidopsis and forms a chitin-induced complex with related kinase CERK1. eLife 3:e03766.

Chinchilla, D., Zipfel, C., Robatzek, S., Kemmerling, B., Nürnberger, T. Jones, J. D., Felix, G., and Boller, T. 2007. A flagellin-induced complex of the receptor FLS2 and BAK1 initiates plant defence. Nature 448:497-500.

Chitwood, D. H., Maloof, J. N., and Sinha, N. R. 2013. Dynamic transcriptomic profiles between tomato and a wild relative reflect distinct developmental architectures. Plant Physiol. 162:537-552.

Choi, H. W., Manohar, M., Manosalva, P., Tian, M., Moreau, M., and Klessig, D. F. 2016. Activation of plant innate immunity by extracellular high mobility group box 3 and its inhibition by salicylic acid. PLoS Pathog. 12:e1005518.

Choi, J., Tanaka, K., Cao, Y., Qi, Y., Qiu, J., Liang, Y., Lee, S. Y., and Stacey, G. 2014. Identification of a plant receptor for extracellular ATP. Science 343:290-294

Cohen, Y., Vaknin, M., and Mauch-Mani, B. 2016. BABA-induced resistance: Milestones along a 55-year journey. Phytoparasitica 44:513-538.

Couto, D., and Zipfel, C. 2016. Regulation of pattern recognition receptor signalling in plants. Nat. Rev. Immunol. 16:537-552.

Dennison, K. L., and Spalding, E. P. 2000. Glutamate-gated calcium fluxes in Arabidopsis. Plant Physiol. 124:1511-1514.

Denoux, C., Galletti, R., Mammarella, N., Gopalan, S., Werck, D., De Lorenzo, G., Ferrari, S., Ausubel, F. M., and Dewdney, J. 2008. Activation of defense response pathways by OGs and Flg22 elicitors in Arabidopsis seedlings. Mol. Plant 1:423-445.

Doke, N. 1983. Involvement of superoxide anion generation in the hypersensitive response of potato tuber tissues to infection with an incompatible race of Phytophthora infestans and to the hyphal wall components. Physiol. Plant Pathol. 23:345-357.

Dromantienè, R., Pranckietienè, I., Šidlauskas, G., and Pranckietis, V. 2013. Changes in technological properties of common wheat (Triticum aestivum L.) grain as influenced by amino acid fertilizers. Zemdirbyste-Agriculture 100:57-62.

El-Mohamedy, R. S. R., Shafeek, M. R., El-Samad, E. E.-D. H. A., Salama, D. M., and Rizk, F. A. 2017. Field application of plant resistance inducers (PRIs) to control important root rot diseases and improvement growth and yield of green bean (Phaseolus vulgaris L.). Aust. J. Crop Sci. 11:496-505.

Fischer, W.-N., André, B., Rentsch, D., Krolkiewicz, S., Tegeder, M., Breitkreuz, K., and Frommer, W. B. 1998. Amino acid transport in plants. Trends Plant Sci. 3:188-195.

Fischer, W. N., Kwart, M., Hummel, S., and Frommer, W. B. 1995. Substrate specificity and expression profile of amino acid transporters (AAPs) in Arabidopsis. J. Biol. Chem. 270:16315-16320.

Friedrich, L., Lawton, K., Ruess, W., Masner, P., Specker, N., Rella, M. G., Meier, B., Dincher, S., Staub, T., Uknes, S., Metraux, J. P., Kessmann, H., and Ryals, J. 1996. A benzothiadiazole derivative induces systemic acquired resistance in tobacco. Plant J. 10:61-70.

Giménez-Ibañez, S., Hann, D. R., Ntoukakis, V., Petutschnig, E., Lipka, V., and Rathjen, J. P. 2009. AvrPtoB targets the LysM receptor kinase CERK1 to promote bacterial virulence on plants. Curr. Biol. 19:423-429.

Görlach, J., Volrath, S., Knauf-Beiter, G., Hengy, G., Beckhove, U., Kogel, K. H., Oostendorp, M., Staub, T., Ward, E., Kessmann, H., and Ryals, J. 1996. Benzothiadiazole, a novel class of inducers of systemic acquired resistance, activates gene expression and disease resistance in wheat. Plant Cell 8:629-643.

Gupta, K. J., Brotman, Y., Segu, S., Zeier, T., Zeier, J., Persijn, S. T., Cristescu, S. M., Harren, F. J., Bauwe, H., Fernie, A. R., Kaiser, W. M., and Mur, L. A. 2013. The form of nitrogen nutrition affects resistance against Pseudomonas syringae pv. phaseolicola in tobacco. J. Exp. Bot. 64:553-568.

Heese, A., Hann, D. R., Giménez-Ibañez, S., Jones, A. M. E., He, K., Li, J., Schroeder, J. I., Peck, S. C., and Rathjen, J. P. 2007. The receptor-like kinase SERK3/BAK1 is a central regulator of innate immunity in plants. Proc. Natl. Acad. Sci. U.S.A. 104:12217-12222.

Henry, G., Thonart, P., and Ongena, M. 2012. PAMPs, MAMPs, DAMPs and others: An update on the diversity of plant immunity elicitors. Biotechnol. Agron. Soc. Environ. 16:257-268.

Hiruma, K., Onozawa-Komori, M., Takahashi, F., Asakura, M., Bednarek, P., Okuno, T., Schulze-Lefert, P., and Takano, Y. 2010. Entry modedependent function of an indole glucosinolate pathway in Arabidopsis for nonhost resistance against anthracnose pathogens. Plant Cell 22: 2429-2443.

Hiruma, K., and Saijo, Y. 2016a. Methods for long-term stable storage of Colletotrichum species. Methods Mol. Biol. 1398:309-312.

Hiruma, K., and Saijo, Y. 2016b. Plant inoculation with the fungal leaf pathogen Colletotrichum higginsianum. Methods Mol. Biol. 1398: 313-318.
Huffaker, A., Pearce, G., and Ryan, C. A. 2006. An endogenous peptide signal in Arabidopsis activates components of the innate immune response. Proc. Natl. Acad. Sci. U.S.A. 103:10098-10103.

Hunt, E., Gattolin, S., Newbury, H. J., Bale, J. S., Tseng, H. M., Barrett, D. A., and Pritchard, J. 2010. A mutation in amino acid permease AAP6 reduces the amino acid content of the Arabidopsis sieve elements but leaves aphid herbivores unaffected. J. Exp. Bot. 61:55-64.

Ichihashi, Y., Kusano, M., Kobayashi, M., Suetsugu, K., Yoshida, S., Wakatake, T., Kumaishi, K., Shibata, A., Saito, K., and Shirasu, K. 2018. Transcriptomic and metabolomic reprogramming from roots to haustoria in the parasitic plant, Thesium chinense. Plant Cell Physiol. 59:729-738.

Ikeuchi, M., Iwase, A., Rymen, B., Lambolez, A., Kojima, M., Takebayashi, Y., Heyman, J., Watanabe, S., Seo, M., De Veylder, L., Sakakibara, H., and Sugimoto, K. 2017. Wounding triggers callus formation via dynamic hormonal and transcriptional changes. Plant Physiol. 175:1158-1174.

Jakab, G., Ton, J., Flors, V., Zimmerli, L., Métraux, J. P., and Mauch-Mani, B. 2005. Enhancing Arabidopsis salt and drought stress tolerance by chemical priming for its abscisic acid responses. Plant Physiol. 139: 267-274.

Jiang, L., Wan, Y., Anderson, J. C., Hou, J., Islam, S. M., Cheng, J., and Peck, S. C. 2017. Genetic dissection of Arabidopsis MAP kinase phosphatase 1-dependent PAMP-induced transcriptional responses. J. Exp. Bot. 68: 5207-5220.

Kadota, Y., Liebrand, T. W. H., Goto, Y., Sklenar, J., Derbyshire, P., Menke, F. L. H., Torres, M. A., Molina, A., Zipfel, C., Coaker, G., and Shirasu, K. 2019. Quantitative phosphoproteomic analysis reveals common regulatory mechanisms between effector- and PAMP-triggered immunity in plants. New Phytol. 221:2160-2175.

Kadota, Y., Shirasu, K., and Zipfel, C. 2015. Regulation of the NADPH oxidase RBOHD during plant immunity. Plant Cell Physiol. 56: 1472-1480.

Kadota, Y., Sklenar, J., Derbyshire, P., Stransfeld, L., Asai, S., Ntoukakis, V., Jones, J. D., Shirasu, K., Menke, F., Jones, A., and Zipfel, C. 2014 Direct regulation of the NADPH oxidase RBOHD by the PRRassociated kinase BIK1 during plant immunity. Mol. Cell 54:43-55

Kadotani, N., Akagi, A., Takatsuji, H., Miwa, T., and Igarashi, D. 2016 Exogenous proteinogenic amino acids induce systemic resistance in rice. BMC Plant Biol. 16:60.

Kim, M. G., da Cunha, L., McFall, A. J., Belkhadir, Y., DebRoy, S., Dangl, J. L., and Mackey, D. 2005. Two Pseudomonas syringae type III effectors inhibit RIN4-regulated basal defense in Arabidopsis. Cell 121: 749-759.

Klessig, D. F., Choi, H. W., and Dempsey, D. A. 2018. Systemic acquired resistance and salicylic acid: Past, present, and future. Mol. PlantMicrobe Interact. 31:871-888.

Krol, E., Mentzel, T., Chinchilla, D., Boller, T., Felix, G., Kemmerling, B., Postel, S., Arents, M., Jeworutzki, E., Al-Rasheid, K. A., Becker, D., and Hedrich, R. 2010. Perception of the Arabidopsis danger signal peptide 1 involves the pattern recognition receptor AtPEPR1 and its close homologue AtPEPR2. J. Biol. Chem. 285:13471-13479.

Kumar, R., Ichihashi, Y., Kimura, S., Chitwood, D. H., Headland, L. R., Peng, J., Maloof, J. N., and Sinha, N. R. 2012. A high-throughput method for Illumina RNA-Seq library preparation. Front. Plant Sci. 3:202.

Kwaaitaal, M., Huisman, R., Maintz, J., Reinstädler, A., and Panstruga, R. 2011. Ionotropic glutamate receptor (iGluR)-like channels mediate MAMP-induced calcium influx in Arabidopsis thaliana. Biochem. J. 440:355-373

Li, F., Wang, J., Ma, C., Zhao, Y., Wang, Y., Hasi, A., and Qi, Z. 2013. Glutamate receptor-like channel3.3 is involved in mediating glutathionetriggered cytosolic calcium transients, transcriptional changes, and innate immunity responses in Arabidopsis. Plant Physiol. 162: 1497-1509.

Li, L., Li, M., Yu, L., Zhou, Z., Liang, X., Liu, Z., Cai, G., Gao, L., Zhang, X., Wang, Y., Chen, S., and Zhou, J. M. 2014. The FLS2-associated kinase BIK1 directly phosphorylates the NADPH oxidase RbohD to control plant immunity. Cell Host Microbe 15:329-338.

Liu, Z., Wu, Y., Yang, F., Zhang, Y., Chen, S., Xie, Q., Tian, X., and Zhou, J. M. 2013. BIK1 interacts with PEPRs to mediate ethylene-induced immunity. Proc. Natl. Acad. Sci. U.S.A. 110:6205-6210.

Luna, E., van Hulten, M., Zhang, Y., Berkowitz, O., López, A., Pétriacq, P., Sellwood, M. A., Chen, B., Burrell, M., van de Meene, A., Pieterse, C. M., Flors, V., and Ton, J. 2014. Plant perception of $\beta$-aminobutyric acid is mediated by an aspartyl-tRNA synthetase. Nat. Chem. Biol. 10: 450-456.

Ma, Y., Walker, R. K., Zhao, Y., and Berkowitz, G. A. 2012. Linking ligand perception by PEPR pattern recognition receptors to cytosolic $\mathrm{Ca}^{2+}$ 
elevation and downstream immune signaling in plants. Proc. Natl. Acad. Sci. U.S.A. 109:19852-19857.

Manzoor, H., Kelloniemi, J., Chiltz, A., Wendehenne, D., Pugin, A., Poinssot, B., and Garcia-Brugger, A. 2013. Involvement of the glutamate receptor AtGLR3.3 in plant defense signaling and resistance to Hyaloperonospora arabidopsidis. Plant J. 76:466-480.

McCarthy, D. J., Chen, Y., and Smyth, G. K. 2012. Differential expression analysis of multifactor RNA-Seq experiments with respect to biological variation. Nucleic Acids Res. 40:4288-4297.

Métraux, J. P., Signer, H., Ryals, J., Ward, E., Wyss-Benz, M., Gaudin, J., Raschdorf, K., Schmid, E., Blum, W., and Inverardi, B. 1990. Increase in salicylic acid at the onset of systemic acquired resistance in cucumber. Science 250:1004-1006.

Meyerhoff, O., Müller, K., Roelfsema, M. R., Latz, A., Lacombe, B., Hedrich, R., Dietrich, P., and Becker, D. 2005. AtGLR3.4, a glutamate receptor channel-like gene is sensitive to touch and cold. Planta 222: 418-427.

Mishina, T. E., and Zeier, J. 2007. Pathogen-associated molecular pattern recognition rather than development of tissue necrosis contributes to bacterial induction of systemic acquired resistance in Arabidopsis. Plant J. 50:500-513.

Miya, A., Albert, P., Shinya, T., Desaki, Y., Ichimura, K., Shirasu, K., Narusaka, Y., Kawakami, N., Kaku, H., and Shibuya, N. 2007. CERK1, a LysM receptor kinase, is essential for chitin elicitor signaling in Arabidopsis. Proc. Natl. Acad. Sci. U.S.A. 104:19613-19618.

Monaghan, J., and Zipfel, C. 2012. Plant pattern recognition receptor complexes at the plasma membrane. Curr. Opin. Plant Biol. 15:349357.

Mousavi, S. A., Chauvin, A., Pascaud, F., Kellenberger, S., and Farmer, E. E. 2013. GLUTAMATE RECEPTOR-LIKE genes mediate leaf-toleaf wound signalling. Nature 500:422-426.

Noutoshi, Y., Okazaki, M., Kida, T., Nishina, Y., Morishita, Y., Ogawa, T., Suzuki, H., Shibata, D., Jikumaru, Y., Hanada, A., Kamiya, Y., and Shirasu, K. 2012. Novel plant immune-priming compounds identified via high-throughput chemical screening target salicylic acid glucosyltransferases in Arabidopsis. Plant Cell 24:3795-3804.

Oostendorp, M., Kunz, W., Dietrich, B., and Staub, T. 2001. Induced disease resistance in plants by chemicals. Eur. J. Plant Pathol. 107: 19-28.

Popko, M., Michalak, I., Wilk, R., Gramza, M., Chojnacka, K., and Górecki, H. 2018. Effect of the new plant growth biostimulants based on amino acids on yield and grain quality of winter wheat. Molecules 23: 470.

Qi, Z., Stephens, N. R., and Spalding, E. P. 2006. Calcium entry mediated by GLR3.3, an Arabidopsis glutamate receptor with a broad agonist profile. Plant Physiol. 142:963-971.

Ranjan, A., Ichihashi, Y., Farhi, M., Zumstein, K., Townsley, B., DavidSchwartz, R., and Sinha, N. R. 2014. De novo assembly and characterization of the transcriptome of the parasitic weed dodder identifies genes associated with plant parasitism. Plant Physiol. 166: 1186-1199.

Robinson, M. D., McCarthy, D. J., and Smyth, G. K. 2010. edgeR: A Bioconductor package for differential expression analysis of digital gene expression data. Bioinformatics 26:139-140.

Ross, A., Yamada, K., Hiruma, K., Yamashita-Yamada, M., Lu, X., Takano, Y., Tsuda, K., and Saijo, Y. 2014. The Arabidopsis PEPR pathway couples local and systemic plant immunity. EMBO J. 33: $62-75$.

Roux, M., Schwessinger, B., Albrecht, C., Chinchilla, D., Jones, A., Holton, N., Malinovsky, F. G., Tör, M., de Vries, S., and Zipfel, C. 2011. The Arabidopsis leucine-rich repeat receptor-like kinases BAK1/SERK3 and BKK1/SERK4 are required for innate immunity to hemibiotrophic and biotrophic pathogens. Plant Cell 23: 2440-2455.

Sato, S., and Yanagisawa, S. 2014. Characterization of metabolic states of Arabidopsis thaliana under diverse carbon and nitrogen nutrient conditions via targeted metabolomic analysis. Plant Cell Physiol. 55: 306-319.

Schindelin, J., Arganda-Carreras, I., Frise, E., Kaynig, V., Longair, M., Pietzsch, T., Preibisch, S., Rueden, C., Saalfeld, S., Schmid, B., Tinevez, J. Y., White, D. J., Hartenstein, V., Eliceiri, K., Tomancak, P., and Cardona, A. 2012. Fiji: An open-source platform for biological-image analysis. Nat. Methods 9:676-682.

Schulze, B., Mentzel, T., Jehle, A. K., Mueller, K., Beeler, S., Boller, T., Felix, G., and Chinchilla, D. 2010. Rapid heteromerization and phosphorylation of ligand-activated plant transmembrane receptors and their associated kinase BAK1. J. Biol. Chem. 285: 9444-9451.
Schwessinger, B., Roux, M., Kadota, Y., Ntoukakis, V., Sklenar, J., Jones, A., and Zipfel, C. 2011. Phosphorylation-dependent differential regulation of plant growth, cell death, and innate immunity by the regulatory receptor-like kinase BAK1. PLoS Genet. 7:e1002046.

Segonzac, C., and Zipfel, C. 2011. Activation of plant pattern-recognition receptors by bacteria. Curr. Opin. Microbiol. 14:54-61.

Seo, S., Nakaho, K., Hong, S. W., Takahashi, H., Shigemori, H., and Mitsuhara, I. 2016. L-histidine induces resistance in plants to the bacterial pathogen Ralstonia solanacearum partially through the activation of ethylene signaling. Plant Cell Physiol. 57:1932-1942.

Shirasu, K., Nakajima, H., Rajasekhar, V. K., Dixon, R. A., and Lamb, C. 1997. Salicylic acid potentiates an agonist-dependent gain control that amplifies pathogen signals in the activation of defense mechanisms. Plant Cell 9:261-270.

Stephens, N. R., Qi, Z., and Spalding, E. P. 2008. Glutamate receptor subtypes evidenced by differences in desensitization and dependence on the GLR3.3 and GLR3.4 genes. Plant Physiol. 146: 529-538

Tanaka, K., Gilroy, S., Jones, A. M., and Stacey, G. 2010. Extracellular ATP signaling in plants. Trends Cell Biol. 20:601-608.

Tateda, C., Zhang, Z., Shrestha, J., Jelenska, J., Chinchilla, D., and Greenberg, J. T. 2014. Salicylic acid regulates Arabidopsis microbial pattern receptor kinase levels and signaling. Plant Cell 26: 4171-4187.

The Gene Ontology Consortium. 2017. Expansion of the Gene Ontology knowledgebase and resources. Nucleic Acids Res. 45:D331-D338.

Thomas, P. D., Campbell, M. J., Kejariwal, A., Mi, H., Karlak, B., Daverman, R., Diemer, K., Muruganujan, A., and Narechania, A. 2003. PANTHER: A library of protein families and subfamilies indexed by function. Genome Res. 13:2129-2141.

Toyota, M., Spencer, D., Sawai-Toyota, S., Jiaqi, W., Zhang, T., Koo, A. J., Howe, G. A., and Gilroy, S. 2018. Glutamate triggers longdistance, calcium-based plant defense signaling. Science 361: 1112-1115.

Trapnell, C., Pachter, L., and Salzberg, S. L. 2009. TopHat: Discovering splice junctions with RNA-Seq. Bioinformatics 25:1105-1111.

Tsuda, K., Sato, M., Glazebrook, J., Cohen, J. D., and Katagiri, F. 2008. Interplay between MAMP-triggered and SA-mediated defense responses. Plant J. 53:763-775.

Vatsa, P., Chiltz, A., Bourque, S., Wendehenne, D., Garcia-Brugger, A., and Pugin, A. 2011. Involvement of putative glutamate receptors in plant defence signaling and NO production. Biochimie 93:2095-2101.

Walker, R., and Lupien, J. R. 2000. The safety evaluation of monosodium glutamate. J. Nutr. 130:1049S-1052S.

Wan, J., Zhang, X. C., Neece, D., Ramonell, K. M., Clough, S., Kim, S. Y., Stacey, M. G., and Stacey, G. 2008. A LysM receptor-like kinase plays a critical role in chitin signaling and fungal resistance in Arabidopsis. Plant Cell 20:471-481.

Ward, E. R., Uknes, S. J., Williams, S. C., Dincher, S. S., Wiederhold, D. L., Alexander, D. C., Ahl-Goy, P., Métraux, J. P., and Ryals, J. A. 1991. Coordinate gene activity in response to agents that induce systemic acquired resistance. Plant Cell 3:1085-1094.

Wehrens, R., and Buydens, L. M. C. 2007. Self- and Super-organizing Maps in R: The kohonen Package. J. Stat. Softw. 21:1-19.

Yamada, K., Yamashita-Yamada, M., Hirase, T., Fujiwara, T., Tsuda, K., Hiruma, K., and Saijo, Y. 2016. Danger peptide receptor signaling in plants ensures basal immunity upon pathogen-induced depletion of BAK1. EMBO J. 35:46-61.

Yamaguchi, Y., and Huffaker, A. 2011. Endogenous peptide elicitors in higher plants. Curr. Opin. Plant Biol. 14:351-357.

Yamaguchi, Y., Huffaker, A., Bryan, A. C., Tax, F. E., and Ryan, C. A. 2010. PEPR2 is a second receptor for the Pep1 and Pep2 peptides and contributes to defense responses in Arabidopsis. Plant Cell 22: 508-522.

Yamaguchi, Y., Pearce, G., and Ryan, C. A. 2006. The cell surface leucinerich repeat receptor for AtPep1, an endogenous peptide elicitor in Arabidopsis, is functional in transgenic tobacco cells. Proc. Natl. Acad. Sci. U.S.A. 103:10104-10109.

Yang, J., Sun, C., Fu, D., and Yu, T. 2017. Test for l-glutamate inhibition of growth of Alternaria alternata by inducing resistance in tomato fruit. Food Chem. 230:145-153.

Yi, S. Y., Shirasu, K., Moon, J. S., Lee, S. G., and Kwon, S. Y. 2014. The activated SA and JA signaling pathways have an influence on flg22-triggered oxidative burst and callose deposition. PLoS One 9: e88951.

Yoshioka, K., Nakashita, H., Klessig, D. F., and Yamaguchi, I. 2001. Probenazole induces systemic acquired resistance in Arabidopsis with a novel type of action. Plant J. 25:149-157. 
Zhang, J., Li, W., Xiang, T., Liu, Z., Laluk, K., Ding, X., Zou, Y., Gao, M., Zhang, X., Chen, S., Mengiste, T., Zhang, Y., and Zhou, J. M. 2010. Receptor-like cytoplasmic kinases integrate signaling from multiple plant immune receptors and are targeted by a Pseudomonas syringae effector. Cell Host Microbe 7:290-301.

Zhu, X., Shaw, P. N., Pritchard, J., Newbury, J., Hunt, E. J., and Barrett, D. A. 2005. Amino acid analysis by micellar electrokinetic chromatography with laser-induced fluorescence detection: Application to nanolitre-volume biological samples from Arabidopsis thaliana and Myzus persicae. Electrophoresis 26:911-919.
Zimmerli, L., Hou, B. H., Tsai, C. H., Jakab, G., Mauch-Mani, B., and Somerville, S. 2008. The xenobiotic beta-aminobutyric acid enhances Arabidopsis thermotolerance. Plant J. 53:144-156.

Zipfel, C., Kunze, G., Chinchilla, D., Caniard, A., Jones, J. D., Boller, T., and Felix, G. 2006. Perception of the bacterial PAMP EF-Tu by the receptor EFR restricts Agrobacterium-mediated transformation. Cell 125:749-760.

Zipfel, C., Robatzek, S., Navarro, L., Oakeley, E. J., Jones, J. D. G., Felix, G., and Boller, T. 2004. Bacterial disease resistance in Arabidopsis through flagellin perception. Nature 428:764-767. 